\title{
Análisis comparativo del manejo forestal de algunos países de Asia y América: 1990-2000
}

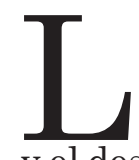
a Cumbre de la Tierra celebrada en Río de Janeiro, Brasil, en 1992, fue el escenario que marcó el antes y el después de los asuntos ambientales en la agenda internacional. Aquí mismo germinó el propósito de manejar los bosques a través de los mecanismos de desarrollo sustentable. Por tal motivo, se exhortó a los países miembros de Naciones Unidas a echar a andar el proyecto por medio de un edicto legal que asegurara el manejo sustentable de los bosques. Es decir, se les pidió a los gobiernos reformar las leyes forestales de sus respectivas naciones.

A partir de entonces, en cada uno de los países miembros de Naciones Unidas, el reto de los legisladores consistió en formular, a partir del hecho de que los recursos forestales son bienes esenciales para la vida del hombre y de los seres vivos que habitan el planeta, un decreto capaz de mediar entre los dueños de los bosques, las fuerzas del mercado, las comunidades que habitan en ellos y la sociedad civil, para que ninguno de ellos sobrepase, en su afán de ejercer sus derechos, los derechos de los demás.

* Profesora e investigadora del Departamento de Estudios del Pacífico, CUCSH-Universidad de Guadalajara. ORCID http:// orcid.org/0000-0002-4553-8141
Desde el punto de vista teórico, una ley forestal integral regida bajo los principios de desarrollo sustentable — como las que se han estado reformando desde principios de la década pasada- determinaría y apaciguaría intereses, lo que podría asegurar el manejo sustentable de los bosques y el bienestar de la humanidad, en cuanto al oxígeno y al cambio climático se refiere. Pero en la práctica las cosas no funcionan así. Aún se siguen presentando malos manejos de los bosques en muchos países del mundo. Prueba de ello es que durante los años noventa se perdieron casi $90 \mathrm{mi}$ llones de hectáreas de bosque en todo el planeta. ${ }^{1}$

Es evidente que en algunos países las leyes forestales no están funcionando. En el quehacer diario algunos -0 todos- los sectores interesados e involucrados consciente e inconscientemente están haciendo mal uso de sus facultades, y la disminución de la cubierta forestal es la prueba irrefutable de ello. La incongruencia entre los propósitos de las leyes y sus resultados concretos lleva a formular preguntas para analizar la relación entre el objetivo mundial y el manejo forestal real nacional. En este sentido, ¿cuál es la situación real del manejo forestal? ¿Cómo podemos medir, con herramientas reales, que en el funcionamiento cotidiano de las economías no se está siendo congruente con lo legalmente 
escrito, y conforme a lo formalmente acordado en la Cumbre de Río? Y por último, ¿por qué en este trabajo se justifica la intervención del Poder Legislativo en el manejo forestal?

Para dar respuesta a las interrogantes anteriores, se propone realizar un análisis comparativo combinando datos cuantitativos y cualitativos de nueve países: Estados Unidos, Canadá, Japón, Brasil, México, Costa Rica, Papúa Nueva Guinea, Indonesia y Myanmar. La importancia de esta selección obedece a que en ellos encontramos países de diferente grado de desarrollo económico, grandes comerciantes de productos madereros y naciones con importante superficie de bosques.

En este sentido, el primer apartado está dedicado a exponer los supuestos teóricos que justifican la intervención pública en los asuntos forestales y la teoría del sistema mundo capitalista, la cual nos llevará a entender el sistema económico de producción, consumo y comercio de, en este caso, los productos forestales.

En el segundo apartado se dará a conocer la superficie forestal, la tasa de deforestación y la tasa de reforestación, así mismo se expondrá la importancia del sector agrícola en cada uno de los países; esto porque se considera que la expansión agrícola es la principal causa de la desaparición de los bosques.

El tercer apartado está dedicado a analizar los recursos forestales dentro de la estructura económica de los países, es decir, examinar las variables relacionadas con la producción forestal nacional y el desarrollo de la industria forestal. Los resultados de estos datos darán la pauta para conocer la balanza comercial de los países.

El cuarto apartado trata del comercio internacional de los productos forestales (cantidades exportadas e importadas, co- mercio total, déficit, superávit). Por último, se concluye el artículo.

\section{Sustento teórico de los recursos forestales}

Samuelson y Nourdhaus analizan los recursos naturales bajo cuatro distinciones: 1. Apropiable o inapropiables, 2. Renovables o no, 3. Bienes esenciales o no esenciales, y 4. Privados o públicos. ${ }^{2}$ En este sentido, los recursos forestales entran en todas las clasificaciones, excepto las no renovables y las no esenciales.

Se argumenta que son apropiables porque los bosques tienen dueños que se benefician de manera económica con la venta de la madera o la tierra. Al mismo tiempo, son inapropiables porque los recursos forestales generan beneficios y costos que van más allá de sus propietarios, es decir: además de la faceta económica, los bosques generan oxígeno, regulan el balance de agua, la temperatura de la tierra, son hogar de una gran diversidad biológica y son fuente de recreación, entre otros. Es decir, todos se benefician de los bosques, aunque no sean los dueños. En este sentido, la pérdida de estas funciones en el proceso de deforestación - de la que nadie se hace responsable- se constituye en externalidades negativas. ${ }^{3}$

Los bosques y las selvas son renovables porque al ser un conjunto dinámico de diversas especies y sistemas sustentables de vida, tienen la capacidad de auto-renovación. Sin embargo, cuando las proporciones de la tala son superiores a la capacidad de auto-conservación que tiene estos bienes, la desaparición de ellos es inminente.

En cuanto a las externalidades positivas de los recursos forestales, como la absorción del dióxido de carbono a cambio de oxígeno limpio, la regulación del balance del agua, el freno al cambio climático, entre

MÉXICO YLACUENCADEL PACÍFICO vol. 9, núm. 27 / enero-diciembre de 2006 
otros, los bosques son esenciales: no existe otro bien que sustituya estas funciones.

Los bosques son bienes privados porque la tenencia de la tierra corresponde a individuos o empresas, sociedades comunales (tales como los ejidos), o al propio gobierno. ${ }^{4} \mathrm{Y}$ son públicos porque las externalidades positivas (o negativas) se pueden suministrar a todo el mundo con tanta facilidad como a una sola persona. ${ }^{5}$

En este sentido, para suministrar de manera eficiente los bienes públicos y los bienes esenciales es indispensable la intervención del Estado por medio de un edicto legal; por lo tanto, la regulación y el manejo de los recursos forestales no deben quedar en la libre fuerza del mercado, pues esto podría llevar a su desaparición.

Hasta aquí se justifica la intervención de una ley forestal que controle y regule el mercado que se genera con los bosques y la toma de decisiones de los dueños de éstos; ahora, veamos el otro lado de la moneda: la teoría de sistema mundo capitalista, la cual nos muestra el manejo mundial de cualquier tipo de bienes, en este caso los productos forestales.

La teoría del sistema mundo capitalista considera que el desarrollo económico de los países depende del lugar que ocupa la nación dentro del sistema económico capitalista. En este sentido, para entender lo anterior es necesario comprender el desarrollo del capitalismo. Según Wallerstein, ${ }^{6}$ debemos considerar el capitalismo como un sistema integral, surgido en Europa, que a través de los años se ha expandido y transcendido cualquier frontera geográfica y política del mundo.

El sistema capitalista está compuesto de un centro, una periferia y una semiperiferia. En el centro se encuentran los estados desarrollados, cuya actividad económica se enfoca en tareas que requieren de mayor grado de cualificación: servicios, tecnología y productos manufacturados. Mientras que en las áreas periféricas se encuentran los países con desarrollo económico bajo, los cuales se caracterizan por tener una gran mayoría de mano de obra no cualificada, cuya actividad se encuentra especialmente en el sector primario y que a través del tiempo ha funcionado como proveedor de materias primas a los estados del centro. Los estados semiperiféricos se encuentran involucrados en una mezcla de actividades productivas, algunas relacionadas con el área del centro y otras con la periferia. ${ }^{7}$

La división anterior supone una jerarquía de tareas ocupacionales, cuyos niveles de capitalización y cualificación se ubican a los estados del centro. Puesto que el fin mismo de la economía mundo capitalista es la acumulación de capitales, incluyendo el humano, el resultado evidente es, por un lado, la tendencia hacia su permanencia en el centro y, por el otro, la mala distribución de los beneficios. El proceso en marcha del capitalismo tiende a aumentar la brecha económica y social entre las distintas áreas de su proceso de desarrollo, especialmente por la inclusión de la tecnología. Es este desarrollo tecnológico el que permite la inclusión o la exclusión de un estado particular en un área distinta, es decir, debido al efecto que trae consigo la aplicación y el uso de la tecnología en un país, como es el incremento de la producción y el desarrollo económico, un país de la periferia puede pasar a la semiperiferia y una de la semiperiferia puede pasar al centro. Aunque los estados del centro siempre se han distinguido por aumentar su capacidad para mantenerse en ese lugar, su permanencia no siempre es asegurada. ${ }^{8}$

De acuerdo con esta teoría, las tres áreas de la economía mundo capitalista se encuentran conectadas dentro de una relación de explotación, donde la riqueza 
es extraída de los países de la periferia y colocada en el centro. Como resultado, la posición de las zonas se destaca más, convirtiendo a los ricos más ricos y a los pobres más pobres.

Por su grado de desarrollo económico, su nivel de productividad y el uso de la tecnología, a Estados Unidos, Canadá y Japón se les considera países del centro; mientras que por su débil estructura económica, Indonesia, Myanmar y Papúa Nueva Guinea son clasificados como países de la periferia. A Brasil, México y Costa Rica, porque presentan características de ambos polos, se les considera como semiperiféricos. Veamos el análisis para corroborar si en el comercio de los productos forestales se cumplen los supuestos de la teoría de sistema mundo capitalista.

\section{La superficie forestal, las plantaciones y la relación de la agricultura con los bosques y las selvas}

El territorio de los nueve países que conforman este grupo representa $25.6 \%$ de la superficie total mundial; sin embargo, en su interior contienen poco más de la tercera parte de la cubierta forestal del mundo. Este hecho los coloca como una fortaleza planetaria, al contribuir con una buena parte a la purificación del oxígeno y dar acogida a una gran diversidad biológica, entre otros beneficios. A nivel doméstico, le brindan a la sociedad la oportunidad de gozar de la explotación comercial inherente a ellos.

$\mathrm{Al}$ mismo tiempo recae en los gobiernos de estos países una gran responsabilidad,

Figura 1

Interrelación de la economía mundo capistalista

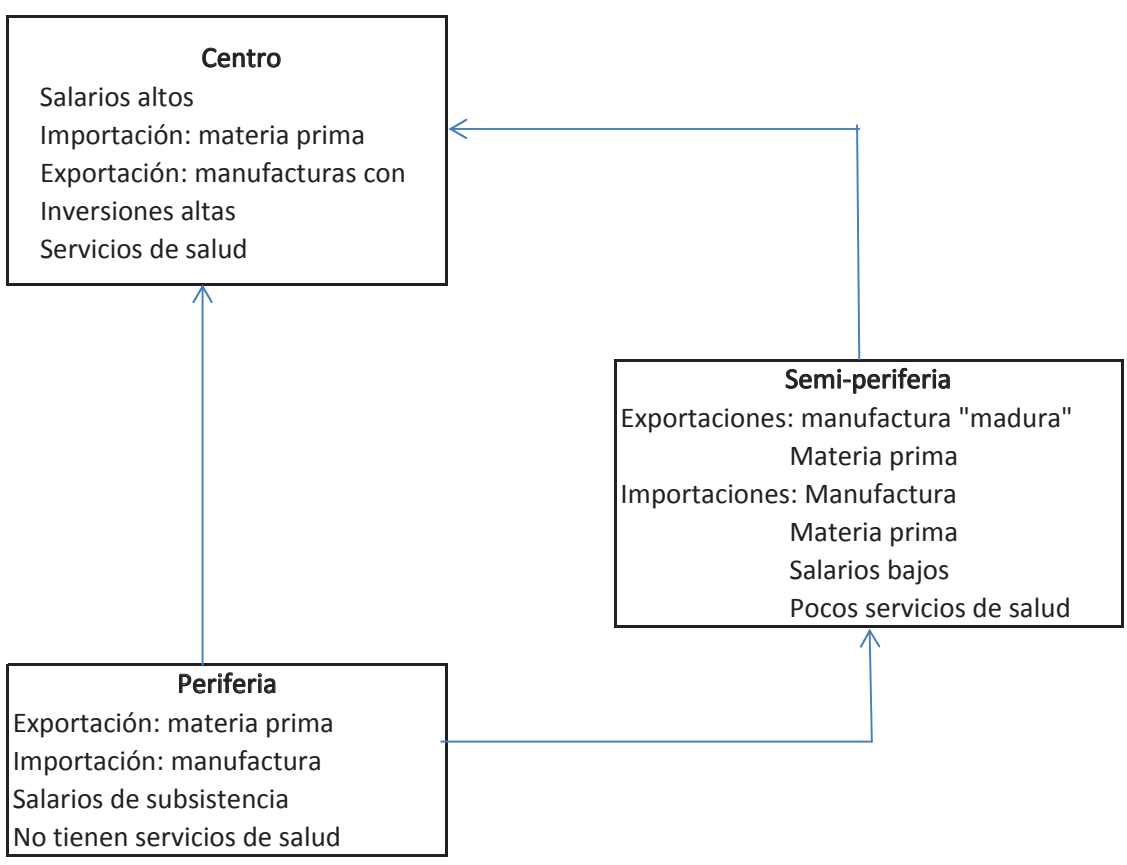

$\longrightarrow \quad$ Dirección del flujo de extracción del excedente 
especialmente para Brasil, Canadá, Estados Unidos e Indonesia, los cuales junto con Rusia conforman poco más de la mitad del área forestal del planeta; ${ }^{9}$ lo que indudablemente los determina como una fortaleza ecológica de la cual depende el bienestar mundial.

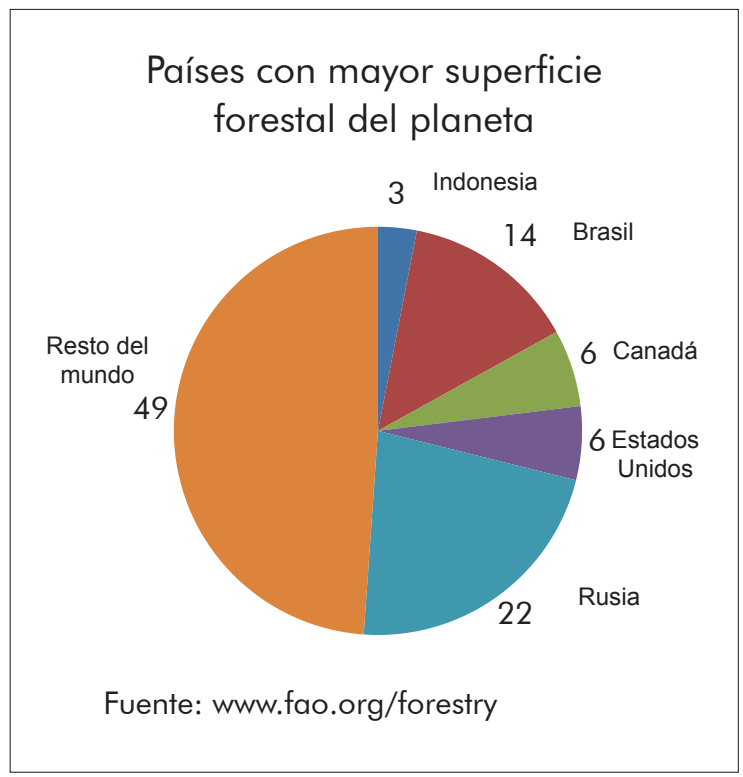

Con excepción de México y Costa Rica, el resto de los países —Japón, Papúa Nueva Guinea y Myanmar- son importantes porque en su espacio territorial la superficie forestal es un factor abundante, debido a que en proporción a su tamaño, en estas economías los bosques representan más de la mitad de su territorio (véase cuadro 1).

Como se puede observar en el cuadro 1, los países que tienen mayor superficie terrestre son Canadá y Estados Unidos, les sigue Brasil; sin embargo, es éste último el que tiene mayor superficie forestal del grupo (41\%). Mientras que de los primeros, Canadá (20\%) cuenta con una mayor área forestal que Estados Unidos (19\%). De manera similar, Indonesia y México territorialmente casi son del mismo tamaño, pero Indonesia tiene más del doble de la cubierta forestal de México.

\section{Deforestación}

A partir de los años noventa, se han venido estableciendo reformas y enmiendas dentro de las leyes forestales al interior de los países, con el objeto primordial de dar a la gestión forestal un manejo sustentable. ${ }^{10}$ En este sentido, tras la concientización y los acuerdos tomados por los gobiernos sobre la importancia de cuidar los bosques, se

\section{Cuadro 1}

\begin{tabular}{lrrrcc}
\hline Países & \multicolumn{1}{c}{$\begin{array}{c}\text { Superficie } \\
(\mathrm{km} 2)\end{array}$} & $\begin{array}{c}\text { Superficie } \\
\text { forestal }(\mathrm{km} 2)\end{array}$ & $\begin{array}{c}\text { Superficie } \\
\text { forestal }(\%)\end{array}$ & $\begin{array}{c}\text { Promedio anual } \\
\text { de deforestación } \\
1990-2000(\mathrm{~km} 2)\end{array}$ & $\begin{array}{c}\text { Promedio anual } \\
\text { de deforestación } \\
1990-2000(\%)\end{array}$ \\
\hline Brasil & $8,547,400$ & $5,384,862$ & 63.0 & 22,264 & 0.4 \\
Canadá & $9,970,610$ & $2,632,241$ & 26.4 & 0 & 0.0 \\
Costa Rica & 51,100 & 19,674 & 38.8 & 158 & 0.8 \\
Estados Unidos & $9,809,630$ & $2,422,979$ & 24.7 & $-3,880$ & -0.2 \\
Indonesia & $1,904,570$ & $1,104,651$ & 58.0 & 11,312 & 1.2 \\
Japón & 337,837 & 223,310 & 66.1 & -34 & 0.0 \\
México & $1,958,200$ & 565,920 & 28.9 & 6,306 & 1.1 \\
Myanmar & 667,580 & 349,144 & 52.3 & 5,169 & 1.4 \\
Papúa Nueva Guinea & 462,840 & 312,880 & 67.6 & 1,129 & 0.4 \\
Total & $33,709,767$ & $13,015,661$ & 38.6 & 42,424 & 5.1 \\
\hline
\end{tabular}

Fuente: elaboración de Ana Bertha Cuevas Tello con datos de World Development Indicator, The World Bank 2002 y www.fao.org/forestry 
esperaría que la degradación fuera menor. Si embargo, según datos de la Food and Agriculture Organization of the United Nations (FAO), la deforestación ${ }^{11}$ de los bosques en los años noventa - aunque ha disminuido considerablemente- es muy alta. En el periodo anterior a la Conferencia de Río (1980-1990), en los países en desarrollo la pérdida anual de los bosques fue de 12.7 millones de hectáreas; posterior a este encuentro, la deforestación promedio anual en este tipo de países fue de 10.7 millones de hectáreas, lo que se traduce en una disminución promedio de sólo dos millones de hectáreas, es decir, una reducción de casi $16 \%$ anual de deforestación, en relación con década anterior. Ahora, si convertimos estas cifras en valores absolutos, podemos afirmar que el decrecimiento de una década a otra en los países en desarrollo salvaguardó 20 millones de hectáreas, cifra relativamente significativa aunque insuficiente desde el punto de vista de un proyecto de vida.

Las causas de la deforestación son muchas. Entre ellas podemos encontrar la utilización de la superficie para otros fines, como la agricultura, la ganadería, el pastoreo, la urbanización, la tasa de crecimiento de la población, el comercio forestal indiscriminado, los sistemas de extracción poco apropiados, las plagas, las enfermedades de los árboles, los incendios y las lluvias torrenciales. ${ }^{12}$

La deforestación promedio anual de los nueve países durante este periodo fue 42 424 km². El país que presentó mayor cantidad de superficie deforestada fue Brasil, ya que durante este periodo tuvo una tasa promedio anual de $22264 \mathrm{~km}^{2}$, es decir, $52 \%$ de la deforestación del grupo. Le siguen Indonesia (27\%), México (15\%), Myanmar (12\%), Papúa Nueva Guinea (3\%) y Costa Rica $(0.3 \%)$ con la mayor deforestación en valores absolutos. Estados Unidos, Japón y Canadá no presentaron reducción; al contrario, recuperaron y extendieron su cubierta a través del método de regeneración natural o de plantaciones.

En relación con su tamaño, los países que presentaron mayor promedio anual de deforestación (valores relativos) fueron Myanmar (1.4\%), Indonesia (1.2\%), México (1.1\%) y Costa Rica (0.8\%); después, Papúa Nueva Guinea y Brasil (0.4\%). Estados Unidos y Japón ampliaron la proporción anual de bosque en $0.2 \%$ y $0.01 \%$, respectivamente. Canadá, entre lo que deforestó y plantó, quedó con las mismas cantidades de bosque.

Como se puede ver, las posiciones de los países cambian según se especifique como valores relativos o absolutos. Veamos el caso de Brasil: este país tiene la mayor deforestación en valores absolutos; sin embargo, en valores relativos tiene la tasa de deforestación más baja, esto quiere decir que como bien público global que son los bosques, Brasil perjudica más que el resto, pero en proporción a su tamaño, se está acabando de manera más lenta sus bosques que Costa Rica (país que en valores absolutos deforestó menos). En este sentido, Myanmar, Indonesia y México son los países que más rápidamente están reduciendo sus bosques.

Con el objeto de facilitar el análisis a la hora de concluir, sintetizo los datos en el siguiente recuadro:

Seis de los nueve países disminuyeron su superficie forestal, dos la aumentaron y uno la mantuvo intacta. La ventaja que le da a Brasil el tamaño de su extensión forestal hace que las enormes cantidades de kilómetros deforestados apenas sean significativas. Sin embargo, podemos ver que la extracción de Indonesia es acelerada, tanto en valores absolutos como en los relativos.

MÉXICO YLACUENCADEL PACÍFICO vol. 9, núm. 27 / enero-diciembre de 2006 
Análisis

Cuadro 2

Superficie forestal 1990-2000

\begin{tabular}{lccc}
\hline Países & Aumentó & $\begin{array}{c}\text { Disminuyó } \\
\text { Permaneció } \\
\text { igual }\end{array}$ \\
\hline $\begin{array}{l}\text { Brasil } \\
\text { Canadá }\end{array}$ & & $* * * *$ & $* * * *$ \\
Costa Rica & & $* * * *$ & \\
$\begin{array}{l}\text { Estados Unidos } \\
\text { Indonesia }\end{array}$ & $* * * *$ & & \\
$\begin{array}{l}\text { Japón } \\
\text { México }\end{array}$ & $* * * * * *$ & \\
$\begin{array}{l}\text { Myanmar } \\
\text { Papúa Nueva }\end{array}$ & & $* * * *$ & \\
Guinea & & $* * * *$ & \\
\hline
\end{tabular}

\section{Plantaciones forestales}

Cuando hablamos de plantaciones forestales debemos distinguir: 1. La reforestación y 2. La forestación. Ambas parten de la acción de la siembra de semillas o de la plantación de árboles pequeños, lo que las distingue es que en la primera el establecimiento es inducido o artificial y la vegetación se desarrolla en terrenos forestales; mientras que en la segunda las plantaciones se establecen en terrenos desprovistos de vegetación natural y son empleados con fines comerciales. ${ }^{13}$ Debido a que algunos países aún no hacen la distinción entre las dos modalidades en sus inventarios, ${ }^{14}$ en este trabajo nos referiremos a ellos sólo como plantaciones.

En el año 2000 los bosques de plantaciones comprendían alrededor de 187 millones de hectáreas en todo el mundo. El 90\% de ellos se implantaron para obtener madera de uso industrial, mientras que $10 \%$ restante tiene como fin suministrar leña o madera a los usuarios a nivel doméstico. Alrededor de $75 \%$ del total de las plantaciones existentes se encuentra en las regiones templadas y el restante $25 \%$ en los trópicos y los subtrópicos. ${ }^{15}$

\section{Gráfica 2}

Países con mayor proporción de plantanciones en el mundo: 2000

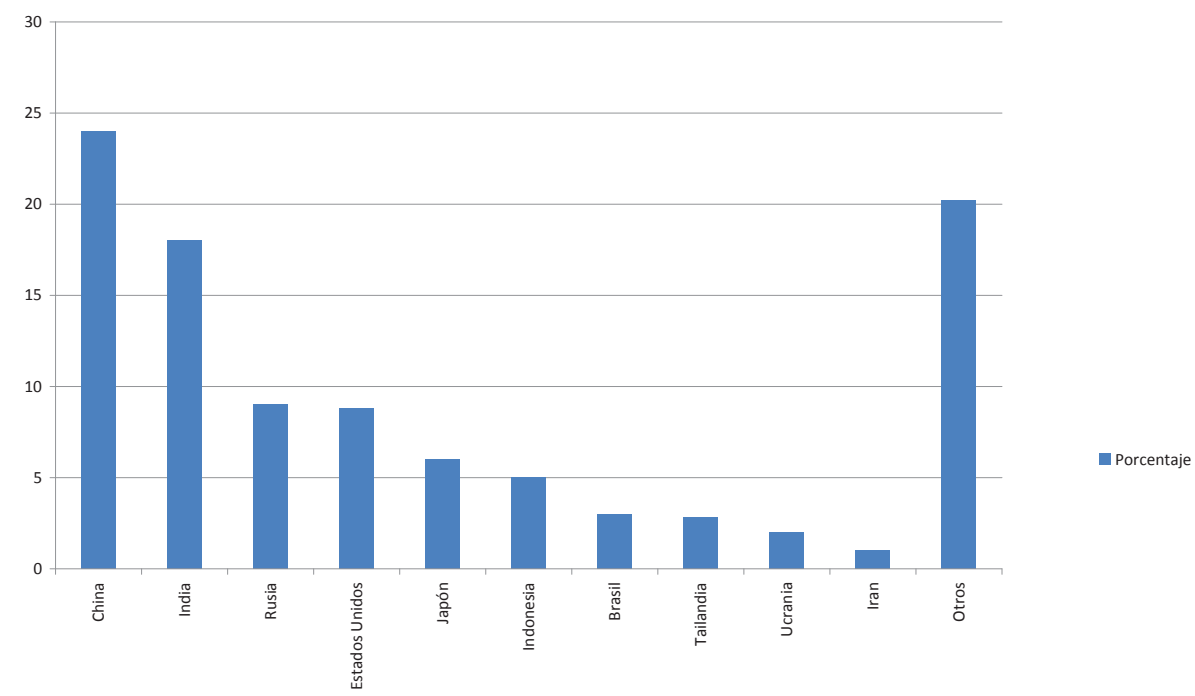

Fuente: Situación de los bosques del Mundo, FAO 
Los países con mayor superficie de plantaciones industriales son China, India, Rusia y Estados Unidos. Los países con una proporción importante de plantaciones destinadas con fines no industriales son India, China, Indonesia y Tailandia. ${ }^{16} \mathrm{Es}$ decir, dentro de nuestra selección contamos con cuatro pioneros en cuanto a métodos de plantaciones forestales se refiere: Estados Unidos, Indonesia, Japón y Brasil.

La importancia de las plantaciones forestales se debe a que surgen como una alternativa ante la evidente disminución de la superficie forestal. Actualmente, los bosques de plantaciones proporcionan alrededor de $10 \%$ de los aprovechamientos de madera y, según palabras de Evans, éstas se están incrementando: "especialmente en el trópico, la tasa actual de plantaciones es de 2 a 3 millones de hectáreas anuales, el doble de la registrada en los años sesenta y setenta". ${ }^{17}$

En este sentido, el hecho de que un país cuente con plantaciones forestales dentro de su territorio resulta una medida preventiva, ya que se incrementa la superficie forestal con los beneficios que esto implica y se preserva la parte comercial de los bosques. Dentro del grupo, unos con más experiencia que otros, todos practican en su territorio algún tipo de plantaciones forestales; sin embargo, en algunos de ellos los perjuicios son mayores que los beneficios, por lo que valdría la pena reflexionar sobre su fiabilidad.

Desde el punto de vista de Humphreys, las plantaciones forestales atienden las necesidades comerciales pero no son una alternativa a la sustentabilidad de los bosques; en primer lugar, porque no proveen de todos los bienes y servicios que los bosques naturales ofrecen: "ellos no mantienen el mismo nivel de biodiversidad, no pueden asegurar la provisión de productos no madereros (nueces, oré- gano, hongos, entre otros) y no proveen los mismos servicios de cultura, espiritualidad y recreación que tienen los bosques naturales". En segundo lugar, porque no pueden asegurar la absorción de dióxido de carbono al ser cortados prematuramente. ${ }^{18}$ El Movimiento Mundial por los Bosques señala tajantemente que las "plantaciones no son bosques", ya que éstos son monocultivos que a gran escala generan impactos negativos en el ámbito social y ambiental; señalan además que las especies de rápido crecimiento como el eucalipto, el pino y la palma aceitera son los que mayor impacto negativo tienen en el planeta. ${ }^{19}$

Entre los impactos negativos a los que se refieren, está el hecho de que al poco tiempo que se instalan los monocultivos forestales a gran escala, éstos comienzan a percibir — y a sufrir- algunos fenómenos:

[...] la fauna autóctona empieza a escasear en el área y en las cercanías de las plantaciones es casi inexistente. Los cambios en el ciclo hidrológico producen escasez de agua y en algunos casos, incluso dan lugar inundaciones superiores a lo normal, luego de intensas lluvias. Las plantas útiles desaparecen. Los cursos de agua se deterioran por causa de la sedimentación resultante de la erosión de suelos generada por las plantaciones. El manejo de las plantaciones genera contaminación química por el intenso uso de agroquímicos. Estos cambios tienen fuertes implicaciones para los medios de vida de las poblaciones locales. La fauna, los peces, los hongos, las frutas, la miel, las verduras forman parte fundamental de su dieta. La disponibilidad segura de agua es básica para sus actividades agrícolas y de cría de animales. ${ }^{20}$

Esto es el lado negativo de las plantaciones forestales.

Desde un punto de vista diferente, Messier, Bigué y Benier dicen que es deseable recurrir a las plantaciones de mayor rendimiento y rápido crecimiento para la producción de madera, debido a que al mismo tiempo que se le da protección a los

MÉXICO YLACUENCADELPACÍFICO vol. 9, núm. 27 / enero-diciembre de 2006 
bosques, se asegura la conservación de la biodiversidad forestal del país. ${ }^{21}$

Tras este debate se inicia el análisis con los países de la muestra. En Estados Unidos los programas de plantación forestal se iniciaron desde la década de los cuarenta, alcanzando niveles sin precedentes en los años ochenta. En la actualidad, las plantaciones forestales lograron incrementar la superficie forestal. "A escala nacional, el crecimiento forestal es mayor que la extracción desde el decenio de 1940." ${ }^{22}$

En Japón este tipo de programas se implementó con el objeto de incrementar y recuperar el patrimonio forestal - dañado tras los estragos de la II Guerra Mundial- desde 1950. ${ }^{23}$ Además, dentro de sus plantaciones forestales, los investigadores japoneses de ingeniería genética están realizando trabajos para estudiar la posibilidad de crear árboles que produzcan más celulosa, fundamental para la industria papelera; en este sentido, el aprovechamiento de árbol sería mayor y se haría más eficiente la producción del país. ${ }^{24}$

En Indonesia, a través de los programas de Desarrollo Estatal, la Comunidad de Desarrollo Forestal y del Desarrollo Forestal de Manglares, desde 1983 continuamente se están programando plantaciones forestales con el objetivo de prevenir la escasez de madera, y para rehabilitar las tierras que fueron taladas en años anteriores; esto con la intención de reducir los problemas sociales y las presiones de la población sobre cuidado del área forestal. ${ }^{25}$

Desde mediados de la década de los sesenta, en la búsqueda de insertar a la nación brasileña en economía internacional, el gobierno militar elaboró un código forestal donde se establecieron incentivos fiscales para aquellos empresarios que invirtieran en plantaciones forestales, dando por resultado la proliferación de plantaciones especialmente de eucalipto.
El desarrollo de esta actividad, que al principio parecía desordenada, llevó a Brasil a convertirse en 1990 en el mayor abastecedor de pulpa de eucalipto en el mundo, al abarcar $80 \%$ del mercado mundial. ${ }^{26}$

Se pensaría que Brasil es el ejemplo a seguir para los países de la periferia y semiperiferia, pero como Carrere y Lohmann lo señalan: "la sociedad en su conjunto ha sufrido una serie de impactos sociales y ambientales negativos" a causa de las plantaciones de eucalipto. En efecto, mientras que las empresas de plantaciones se expanden bajo la bandera del desarrollo sustentable, el daño social y ecológico es enorme. El deterioro ecológico proviene de los empresarios en su afán de incrementar la producción de su empresa, lo que disminuye anualmente miles de hectáreas de selva natural, sin contar con que sus eucaliptales secan el curso del agua, destruyen la fauna local, causan empobrecimiento del suelo, impiden la regeneración de las especies de vegetación nativa y reducen drásticamente el área de alimentos básicos. ${ }^{27}$

En la reforma a la Ley Forestal de 1997, el gobierno de México desarrolló un apartado dedicado a las plantaciones, el cual incluye el derecho de las compañías a asociarse con los campesinos dueños de la tierra. Pero, como señala el Movimiento Mundial por los Bosques, la presión que ejercieron las organizaciones campesinas, los ambientalistas y la sociedad civil —así como, en menor medida, algunos partidos políticos- logró que se estipulara dentro del marco legal, para beneficio de todos, que las plantaciones no pueden establecerse en áreas boscosas y se fijaron determinadas condiciones para las plantaciones a gran escala, incluyendo planes de manejo y evaluaciones de impacto ambiental. ${ }^{28}$

A través de la Semarnap se puso en marcha un programa de establecimiento 
de plantaciones forestales (Prodeplan), en el cual se prevén incentivos económicos a los dueños de los bosques que establezcan plantaciones en tierras degradadas y abandonadas. ${ }^{29} \mathrm{Al}$ igual que en México, en Costa Rica históricamente el mercado maderero se ha limitado al aprovechamiento de los bosques naturales; pero desde la década de los ochenta se reforesta con diferentes especies. Fue en 1996 cuando a través del marco legal, ${ }^{30}$ se reconocieron oficialmente los servicios ambientales de bosques naturales y plantados. ${ }^{31}$

Las plantaciones en Myanmar desempeñan un papel minoritario en el manejo de los bosques. En este país, las plantaciones establecidas tienen dos propósitos: que sean comercialmente operables y restaurar las tierras forestales degradas. ${ }^{32}$ Es importante señalar que desde 1856 en Myanmar se iniciaron las plantaciones de Teca — especie financieramente más rentable que cualquier otra alternativa-. La superficie forestal de esta especie fue en aumento hasta la última década del siglo XX, llegando a abarcar en 1994, 565,200 acres. Pero Saw Keh señala que "este tipo de árbol genera un efecto destructivo sobre el suelo. Así, el monte bajo poca teca o mucha teca se convierte en insano y escaso". ${ }^{33}$ En este sentido, las plantaciones de dicha variedad traerán en el mediano plazo efectos adversos al medio ambiente, lo que quizá, junto con su extracción comercial, terminará en la deforestación paulatina de los bosques naturales.

Aunque Kasonwsky nos dice que "las plantaciones tanto de Canadá como de Papúa Nueva Guinea son demasiado incipientes", ${ }^{34}$ éstas no dejan de estar presentes en algunos sitios de dichos países. En Canadá se han utilizado varios tipos de híbridos de álamo (Populus) en operaciones de plantaciones intensivas; en la práctica la podemos encontrar en Ontario y en el sur de Columbia Británica, llegando a extenderse a 7,000 hectáreas en toda la nación. ${ }^{35}$

Mientras que en Papúa Nueva Guinea la mayoría de las plantaciones son ejecutadas por el Estado, pero resultan poco exitosas debido al descuido y al abandono. Actualmente en este país se permitieron las plantaciones al sector privado, las cuales empiezan a fructificar. En este sentido, las tres principales compañías que promueven las plantaciones son empresas japonesas, a través de la inversión extranjera directa. ${ }^{36}$

En suma, recurrir a las plantaciones forestales no es la panacea para resolver todos los problemas que implica la reducción de la superficie forestal. Es claro que los bosques naturales no tienen sustitución en el total de sus funciones. Debe quedar entendido, tras el debate anterior, que: 1. La finalidad principal de las plantaciones es comercial-económica; 2. Que garantizar la oferta de madera no es cualquier cosa, en este sentido las plantaciones tienen un lado positivo; 3. Que los bosques naturales se deben seguir protegiendo; 4. Que se debe de apoyar la regeneración natural; 5. Que en algunos países el manejo de las plantaciones es mejor que en otros, en el sentido de la regulación de los efectos negativos; 6. Que se deben seguir elaborando trabajos de investigación para frenar las consecuencias degradantes de las plantaciones e impulsar los efectos positivos; 7. No se debe tratar de reemplazar los bosque naturales con plantaciones.

\section{El sector agrícola y su relación con los bosques}

A través de los años, diversos estudios científicos han concluido que la expansión agrícola es una de las principales causas de la deforestación de la superficie forestal.

MÉXICO YLACUENCADEL PACÍFICO vol. 9, núm. 27 / enero - diciembre de 2006 
Según datos de la FAO, las tierras agrícolas se están expandiendo en casi $70 \%$ de los países, declinando en $25 \%$ y manteniéndose sin cambios en el restante 5\%. En las dos terceras partes de los países donde la tierra agrícola se expandió, el área forestal decreció, pero en la otra tercera parte los bosques se están incrementando. En $60 \%$ de los países donde la tierra agrícola está decreciendo, los bosques se están expandiendo, mientras que en los restantes (36\%), los bosques están siendo reducidos. ${ }^{37}$

Con estos resultados podemos analizar que si bien la deforestación tiene relación directa con la expansión de las tierras agrícolas, el aumento de éstas no necesariamente está acompañado de la disminución de la tierra forestal. Además, la expansión forestal no genera, necesariamente, la disminución de la superficie agrícola. Considerando que dentro de un país las factores son limitados, en las naciones donde al mismo tiempo están aumentando la superficie forestal y la agrícola, podemos suponer que anterior a este suceso ya existía algún tipo de superficie forestal degradada y que actualmente se está rehabilitando, y que las innovaciones tecnológicas actuales permiten que se utilice como tierra agrícola o forestal, superficies que anteriormente eran consideradas como no aptas para la agricultura.

El valor agregado agrícola nos señala el porcentaje con que la actividad contribuye al PIB nacional. En Myanmar este sector tiene un peso determinante: $60 \%$. En Papúa Nueva Guinea e Indonesia la agricultura es relativamente importante, ya que contribuye con $26 \%$ y $17 \%$, respectivamente. Para Costa rica y Brasil esta actividad proporciona $9 \%$ y $7 \%$, en cada uno de ellos. Con un dato menor figuran: México (4\%), Canadá (3\%), Estados Unidos

Cuadro 3

El sector agrícola en la economía

\begin{tabular}{|c|c|c|c|c|c|c|}
\hline & $\begin{array}{l}\text { Estructura de } \\
\text { la producción } \\
2000\end{array}$ & pok & lación rural & Fuerza labo & ral agrícola & $\begin{array}{c}\text { Crecimiento de } \\
\text { la productividad } \\
\text { agrícola }\end{array}$ \\
\hline Países & $\begin{array}{c}\text { Valor agregado } \\
\text { agrícola como } \\
\text { porcentaje del } \\
\text { PIB }\end{array}$ & $\begin{array}{l}\text { Porcentaje } \\
\text { del total } \\
2000\end{array}$ & $\begin{array}{c}\text { Porcentaje } \\
\text { promedio anual } \\
\text { de crecimiento } \\
1980-2000\end{array}$ & $\begin{array}{l}\text { Masculina } \\
1998-2000\end{array}$ & $\begin{array}{c}\text { Femenina } \\
\text { 1998-2000 }\end{array}$ & $\begin{array}{c}\text { Crecimiento } \\
\text { promedio anual } \\
1990-2000\end{array}$ \\
\hline Brasil & 7 & 19 & -1.3 & 26 & 19 & 3.2 \\
\hline Canadá & ${ }^{\circ} 3$ & 23 & 0.8 & 5 & 2 & 1.1 \\
\hline Costa Rica & 9 & 48 & 1.7 & 27 & 5 & 4.1 \\
\hline Estados Unidos & 1.7 & 23 & 0.4 & 4 & 1 & N.D. \\
\hline Indonesia & 17 & 59 & 0.4 & -57 & $* 54$ & 2.1 \\
\hline Japón & 1 & 21 & -0.2 & 5 & 6 & -3.2 \\
\hline México & 4 & 26 & 0.5 & 27 & 9 & 1.8 \\
\hline Myanmar & 60 & 72 & 1.5 & N.D. & N.D. & 5.3 \\
\hline $\begin{array}{l}\text { Papúa Nueva } \\
\text { Guinea }\end{array}$ & 26 & 83 & 2.3 & *92 & *92 & 3.7 \\
\hline
\end{tabular}

Fuente: Elaboraciòn de Ana Bertha Cuevas Tello con datos del World Development Indicator, The World Bank 2002

Nota: * 1980-1982,

$\circ 1990$ 
(1.7\%) y Japón (1\%), donde este sector contribuye relativamente al PIB.

Ahora, veamos el porcentaje de la población que vive en el campo. El mayor porcentaje de los ciudadanos de Papúa Nueva Guinea (83\%), Myanmar (72\%), Indonesia (59\%), y en menor medida de Costa Rica (48\%), viven en la zona rural. Mientras que el porcentaje de la población de México, Canadá, Estados Unidos y Japón, que no vive en la zona urbana oscila entre $21 \%$ y $26 \%$. En estos mismos países, el promedio anual de crecimiento de la población rural es mayor: en Papúa Nueva Guineas (2.3\%), Costa Rica (1.7\%) y Myanmar (1.5\%). En Canadá (0.8\%), México (0.5\%), Estados Unidos e Indonesia (ambos con 0.4\%) se dio un crecimiento relativamente bajo. Mientras que en Brasil (-1.3\%) y Japón $(-0.2 \%)$ el número de personas que radican en el campo está disminuyendo.

La mayor proporción de la fuerza productiva que labora dentro del sector agrícola la tienen Papúa Nueva Guinea (84\%) e Indonesia (56\%). En el primero, casi la totalidad de las mujeres en edad productiva trabaja en esta actividad, y en el segundo es casi proporcional. De Myanmar no se tiene dato, pero en relación con el resto de las variables señaladas en el cuadro, se deduce que tiene un amplio porcentaje de población laboral en esta actividad. En México (18\%), Costa Rica (16\%) y Brasil (22.5\%) la fuerza productiva (promediando hombres y mujeres) que laboran en el campo es relativamente importante. Mientras que en Estados Unidos y Canadá el número de personas que vive en la zona rural y que se emplea en este rubro no llega a 3.5\%. En Japón sólo 5.5\% trabaja en el sector agrícola.

En la década de los noventa, los países que presentaron mayor crecimiento promedio anual de la productividad del sector agrícola fue Myanmar (5.3\%), Costa
Rica (4.1\%), Papúa Nueva Guinea (3.7\%) y Brasil (3.2\%), por ser los que concursaron con mayor porcentaje. Indonesia mostró un crecimiento de productividad anual de $2.1 \%$. El aumento de la productividad de Canadá y México no llegó a dos por ciento; y en Japón su crecimiento fue negativo $(-3.2 \%)$.

Con este cuadro se puede confirmar que la superficie agrícola no ha permanecido estática: en algunos países ha disminuido y en otros ha aumentado. El país que presentó mayor crecimiento anual fue Papúa Nueva Guinea (1.3\%), le siguen Brasil (0.79\%), México (0.37\%), Myanmar $(0.36 \%)$ y en menor medida Costa Rica (0.09\%). Caso contrario, los países que disminuyeron su superficie agrícola durante este tiempo fueron Japón (0.84\%), Estados Unidos (0.33\%), Canadá (0.03\%), e Indonesia (0.07\%). El caso de este último llama la atención porque a principios de la década redujo su superficie agrícola 8\%; sin embargo, es claro que desde 1996 el país no ha dejado de expandir terrenos dedicados a este fin —de hecho, de 1996 a 2000, el crecimiento promedio anual fue de $1.8 \%$ (superior al de Papúa Nueva Guinea).

Papúa Nueva Guinea y Brasil son los únicos países en los que la superficie agrícola no dejó de expandirse en ningún año de la década. El caso de México es diferente porque mostró crecimiento de los terrenos agrícolas durante la primera mitad de los años noventa, posteriormente la superficie permaneció sin cambios durante cuatro años, para volver a incrementarse en 2000. Durante este periodo, Costa Rica sólo aumentó su superficie agrícola en 19911992, 1994 y 1999; el resto la mantuvo sin cambios o la disminuyó. En seis de diez años del periodo, Myanmar aumentó su cubierta forestal: especialmente en 2000 fue significativo (2.1\%).

MÉXICO YLACUENCADEL PACÍFICO vol. 9, núm. 27 / enero-diciembre de 2006 


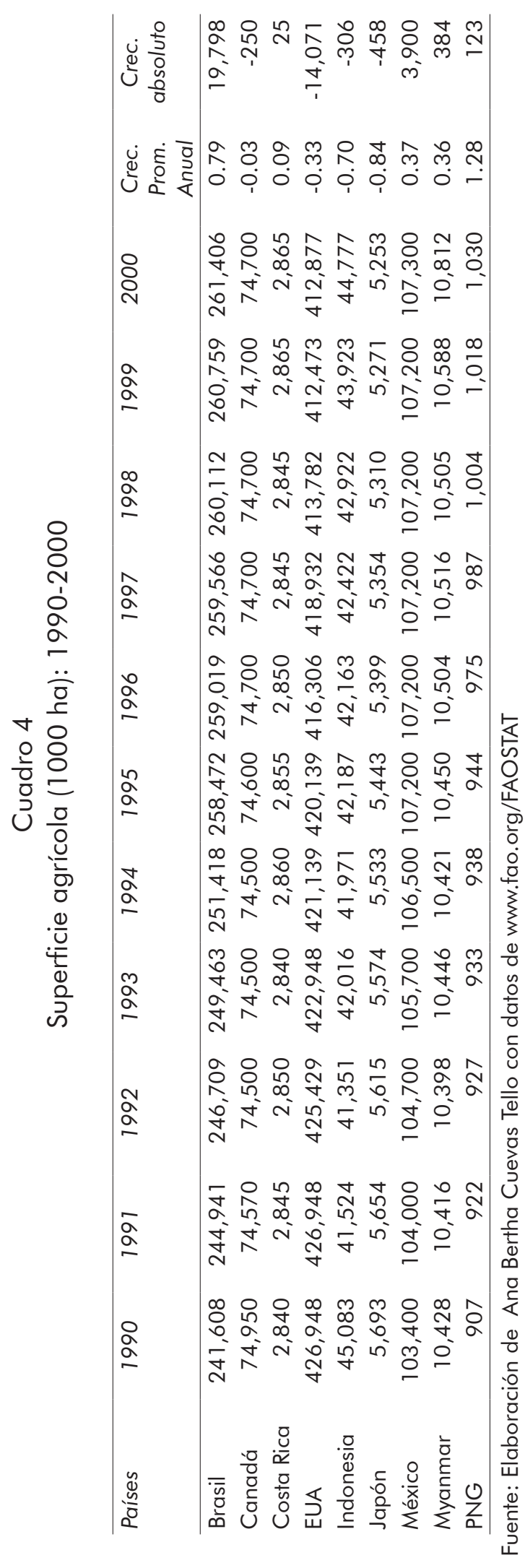

Los países donde la superficie agrícola disminuyó, a excepción de Indonesia, son los mismos donde el sector agrícola es relativamente poco importante en el PIB: Canadá, Estados Unidos y Japón. Es relevante señalar que este dato coincide con la funcionalidad del proyecto de plantaciones forestales que tienen Japón, Estados Unidos e Indonesia, de lo que se puede deducir que las tierras que se están dejando de cultivar las están usando con fines forestales. Aunque parece que las políticas de Indonesia están cambiando en los últimos años del análisis, ya que la superficie agrícola está aumentando.

El cuadro 5 nos muestra la relación de crecimiento de la superficie agrícola con la disminución de la cubierta forestal. Podemos ver que en Brasil la superficie agrícola representa la mitad de la cubierta forestal; sin embargo, mientras la primera aumentó durante los años noventa a 2067 miles de hectáreas, la segunda disminuyó casi en las mismas proporciones que la primera (2 176 miles de hectáreas), lo que representa 95\%. En este sentido, los datos muestran que en este país existe una estrecha relación entre la disminución de la superficie forestal y el incremento del área agrícola.

En Canadá la superficie agrícola representa una tercera parte de la forestal y existe evidencia de que la superficie agrícola tiende a disminuir. Como la cubierta de los bosques se mantuvo sin cambios, faltan pruebas para señalar que a las tierras agrícolas se les dio uso forestal, por lo que tal vez sea para fines urbanísticos.

En Costa Rica la superficie forestal es menor que la agrícola, pero la cantidad cubierta deforestada fue casi seis veces mayor a lo que se incrementó de tierras dedicadas a la agricultura. Se puede deducir que parte de las tierras deforestadas en la 
Cuadro 5

Relación de la variable deforestación y crecimiento de la superficie agrícola: 1990-2000

\begin{tabular}{|c|c|c|c|c|}
\hline Países & 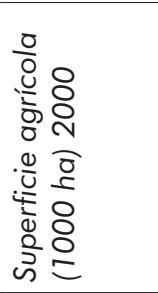 & 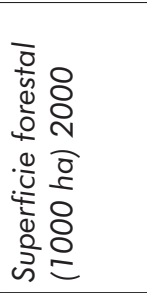 & 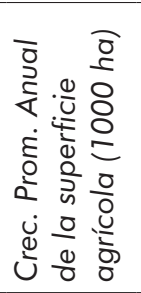 & 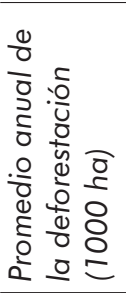 \\
\hline Brasil & 261,406 & 543,905 & 2,067 & 2,176 \\
\hline Canadá & 74,700 & 244,571 & -25 & 0 \\
\hline Costa Rica & 2,865 & 1,968 & 3 & 16 \\
\hline $\begin{array}{l}\text { Estados } \\
\text { Unidos }\end{array}$ & 412,877 & 255,993 & $-1,381$ & -512 \\
\hline Indonesia & 44,777 & 104,986 & -30 & 1,260 \\
\hline Japón & 5,235 & 24,081 & -44 & 0 \\
\hline México & 107,300 & 55,205 & 398 & 607 \\
\hline Myanmar & 10,812 & 34,419 & 39 & 482 \\
\hline $\begin{array}{l}\text { Papúa } \\
\text { Nueva } \\
\text { Guinea }\end{array}$ & 1,030 & 30,601 & 13 & 122 \\
\hline
\end{tabular}

Fuente: Elaboración de Ana Bertha Cuevas Tello con datos de www.fao.org/FAOSTAT

década fueron empleadas para uso agrícola y el resto para otros fines.

En Estados Unidos el espacio agrícola es $40 \%$ mayor que el área forestal. Los datos muestran que la primera disminuyó, mientras que la segunda aumentó. En este sentido, por contar este país con grandes extensiones de plantaciones, existen elementos para afirmar que algunas de estas tierras agrícolas se están empleando con fines forestales, y el resto para urbanización.

En Indonesia la superficie agrícola representa $42 \%$ del plano forestal. Podemos ver que ambas cubiertas disminuyeron durante 1990-2000; sin embargo, las cantidades de hectáreas deforestadas fueron mucho mayores que la disminución de las tierras agrícolas. La tendencia de los últimos cuatro años de la década (1997-2000) nos dice que la extensión agrícola creció en promedio anual $1.5 \%$, lo que representa 671 miles de hectáreas, la mitad del promedio anual de deforestación. Se deduce que en este país la mitad de las tierras que se deforestan están siendo usadas con objetivos agrícolas.

En Japón la superficie agrícola representa casi la quinta parta del área forestal. En promedio, este país disminuyó su cubierta agrícola 44000 hectáreas y aumentó su cubierta forestal en promedio anual 3 000, lo que se establece que parte de la extensión que dejó de emplearse en la agricultura se utiliza en plantaciones y el resto, por la presión demográfica, se destinó a fines urbanísticos.

La superficie agrícola de México es casi el doble de la forestal. En la década de los noventa la extensión de la tierra arable aumentó en promedio anual 398000 hectáreas, mientras que la superficie forestal disminuyó casi el doble. En este sentido, la mitad de la cubierta deforestada se destina a la agricultura, y el resto cambió a usos urbanos.

En 2000 la superficie agrícola de Myanmar era casi un tercio de la cubierta forestal. Este país aumentó la superficie agrícola 39000 hectáreas, es decir, 8\% de la cantidad de extensión de bosques deforestado (482 000 hectáreas): estos datos representan la relativamente baja relación entre el aumento de la extensión agrícola y la disminución de los bosques.

En Papúa Nueva Guinea la tierra agrícola representan 3\% de la extensión forestal, aun cuando la primera aumentó en promedio anual 13000 hectáreas y cuando la cubierta forestal disminuyó en promedio 122000 hectáreas; es decir, el crecimiento de la superficie agrícola representa $11 \%$ de la disminución de la cubierta forestal. Así, aunque la relación deforestación-incremento del área agrícola

MÉXICO YLACUENCADELPACÍFICO vol. 9, núm. 27 / enero - diciembre de 2006 
es relativamente baja, está presente.

En suma, en los países de desarrollo económico medio la relación agriculturadeforestación es relativamente estrecha, y en los países con desarrollo bajo disminuye (porque la agricultura no es la principal causa de la deforestación). En los países desarrollados, aparentemente la relación se invierte, las tierras que se descartan de ser empleadas en la agricultura son utilizadas, entre otras tantas cosas, para fines forestales.

\section{Los recursos forestales dentro de la estructura económica de los países}

Paul Samuelson dice que la capacidad productiva de un país depende "del tamaño de la población activa, de la cantidad y de la calidad del stock de capital, de los conocimientos técnicos del país, así como de la capacidad para utilizarlos y de la naturaleza de las instituciones públicas y privadas". ${ }^{38}$ Dentro de los factores elementales de producción (la tierra, el trabajo y el capital), la cantidad de superficie forestal es importante para la economía del país por los múltiples productos madereros y no madereros que se comercializan de ellos. Se estima que el sector de productos forestales contribuye entre $2 \%$ y $3 \%$ del producto interno bruto mundial y representa 3\% del comercio de mercaderías internacionales..$^{39} \mathrm{El}$ movimiento anual de la madera en rollo, madera aserrada, pulpa y papel excede la suma de 200,000 millones de dólares estadounidenses, esto sin contar con los productos forestales no madereros, los cuales son difíciles de estimar en términos monetarios pero que son de primordial importancia para una población estimada de 600 millones de personas — sólo en países en desarrollo—. ${ }^{40}$ El Banco Mundial estima que de $1.2 \mathrm{mi}$ llones de personas que viven en extrema pobreza, $90 \%$ depende de los bosques y sus productos para sobrevivir. ${ }^{41}$

La industria forestal

Semerena y Aroche afirman:

[...] la industria forestal inicia con la tala de árboles y su procesamiento en diferentes tipos de cortes, la producción de pulpa y de papel, aglomerado y otras más. En cada una de ellas se requiere de diferente tipo de tecnología, infraestructuras y escala de producción. Además, todos estos requerimientos varían también de acuerdo con las condiciones locales y regionales que tengan los recursos forestales en explotación, tipos de productos que se generen y los mercados de destinos. ${ }^{42}$

Dentro de la industria forestal podemos distinguir dos grandes ramas: 1 . La industria de corte y procesamiento de madera, que en su mayoría produce medios intermedios; 2 . La industria de la madera, donde se produce la pulpa, papel, triplay, chapa, entre otras, que aporta el mayor valor agregado. La decisión de un país de optar por una u otra actividad industrial (o por ambas) depende, como lo señala Heckscher-Ohlin, "de la dotación relativa de factores y de la intensidad factorial relativa". En este sentido, los países producirán conforme a su abundancia relativa de factores (trabajo, tierra o capital), el bien que en su elaboración requiera más del factor abundante..$^{43}$

Así, se espera que en los países con desarrollo bajo opten por el primer tipo de industria porque no requiere una gran inversión en capital, ni en capacitación humana, mientras que emplearían tecnologías que aprovechen el factor más barato y abundante: el trabajo. Los países con desarrollo alto destacarían en la industria que requiere mayor intensidad relativa de capital, al mismo tiempo que aprovechan los beneficios de sus bosques, no dejarían la 
utilidad de producir en las industrias que requieren de poco valor agregado.

\section{La industria 1}

Como se puede apreciar en el cuadro siguiente, los países de la selección que mayores cantidades de madera aserrada produjeron durante 1990-2000 (industria 1) son Estados Unidos (46.3\%), Canadá (18.4\%), Brasil (16\%) e Indonesia (10.5\%), ya que juntos representan $91 \%$ del total de madera - del grupo — que produjo durante los diez años. Papúa Nueva Guinea y Costa Rica, con relación al resto de los países, son los que tuvieron menor producción. El dato de Papúa Nueva Guinea sorprende porque el sector forestal es una actividad muy importante para este país y la superficie forestal es un factor abundante. Esto podría indicar que en dicho país las condiciones de producción son mínimas, por lo que no puede ser tan eficiente, ya que como se vio en el cuadro 1 la superficie forestal de este país se disminuyó en los años noventa (es decir, sí están haciendo uso de los árboles, pero pudiera ser que se esté presentando tala clandestina).

La producción de madera aserrada en su conjunto no presentó grandes tasas de crecimiento promedio anual en el total del grupo, ya que sólo fue de $0.4 \%$. El país que mostró más crecimiento positivo fue Myanmar (5.4\%); le siguen con 2.7 puntos porcentuales Canadá, luego Costa Rica (2.1\%); posteriormente Brasil (1.5\%) y México (con menos de 1\%). El país que disminuyó de manera relativamente acelerada su producción fue Japón: 4.5\%, hecho que corresponde cabalmente a la política japonesa de cuidar la superficie forestal del país y es acorde con el aumento de la cubierta forestal del país. Indonesia, Papúa Nueva Guinea y Estados Unidos también forman parte de los países que

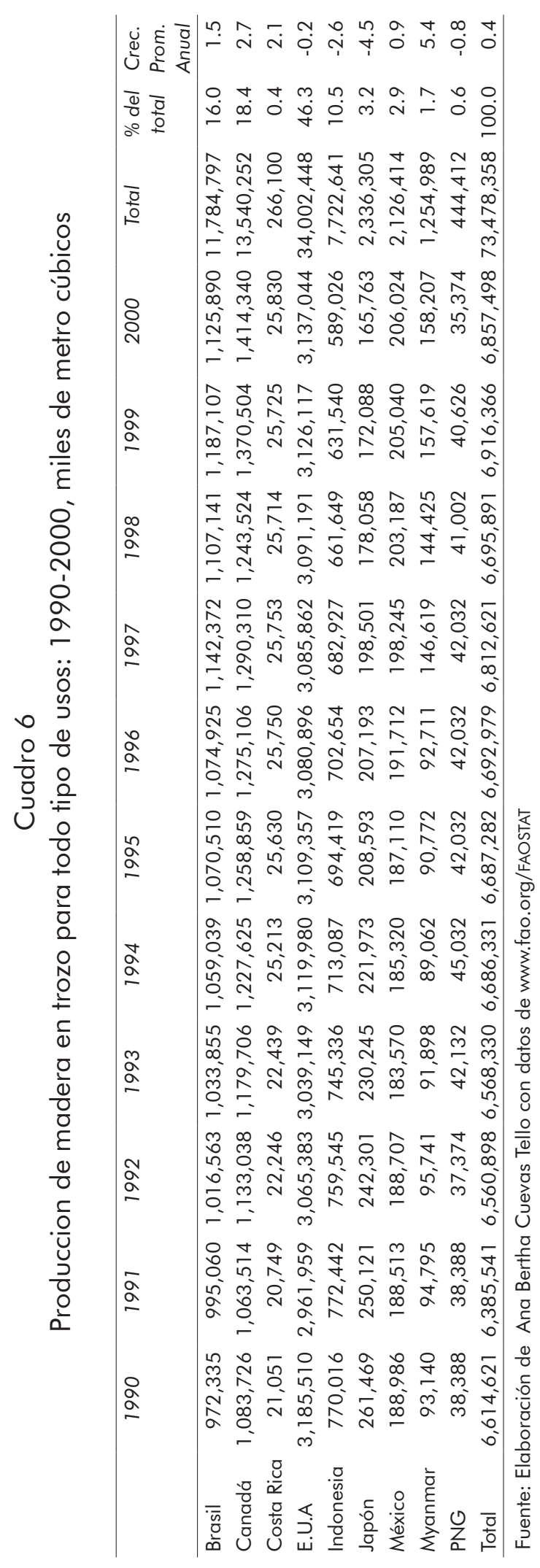

MÉXICO YLACUENCADEL PACÍFICO vol. 9, núm. 27 / enero-diciembre de 2006 
presentaron disminución promedio de la producción forestal.

Los países con mayores volúmenes de producción en la industria 1, durante la década de los noventa, son: Estados Unidos (con una participación de más de $46 \%$ del total del grupo), le siguen Canadá (18.4\%), Brasil (16\%) e Indonesia (10.5\%). Las cantidades producidas por México y Japón fueron muy semejantes (alrededor de $3 \%$ del total del grupo). La producción de Myanmar, Papúa Nueva Guinea y Costa Rica fue relativamente baja: para el primero representa $1.7 \%$ por ciento y para las dos últimas $0.6 \%$ y $0.4 \%$, respectivamente.

Así, los países con mayor superficie forestal son los que mostraron mayor producción; sin embargo, aunque Brasil tiene casi el doble de la cubierta forestal de Estados Unidos y Canadá, su producción quedó en tercer lugar. Al mismo tiempo, su área forestal es cinco veces más grande que la de Indonesia y sin embargo su producción sólo es $35 \%$ mayor que la de este país. Asimismo, Indonesia cuenta con sólo el doble de la extensión forestal de México, pero su producción es tres veces superior. El área forestal de Japón está por debajo de la mitad de la de México, no obstante su producción fue superior en $8 \%$ a la de éste último. La superficie forestal de Myanmar y Papúa Nueva Guinea es muy semejante, pero la producción del primero supera casi tres veces a la del segundo país.

Estos datos confirman que las industrias de determinados países son más eficientes que otras, o que algunos países cuentan con tecnología más sofisticada. Vemos, por ejemplo, que de los tres países con mayor extensión forestal, Estados Unidos es relativamente más productivo que Canadá, y que la industria de estos dos es más fructífera que la de Brasil, e incluso, la industria de Indonesia (con tamaño medio del área forestal) es más eficaz que la brasileña. La industria de Japón es más eficiente que la de México, y la de Myanmar que la de Papúa Nueva Guinea.

\section{La industria 2}

Estados Unidos continúa siendo, por mucho, el principal productor en la industria forestal de mayor valor agregado, y de los que requieren superior grado de inversión - donde se produce pulpa y todo tipo de papel-. De los 13.219 millones de toneladas métricas que se produjeron en el grupo durante la última década del siglo Xx, Estados Unidos contribuyó con $60 \%$; por lo tanto, es evidente que este país es relativamente más productivo en la industria 2 que en la 1 (46\%). Le sigue con mayor producción Japón (17\%) y Canadá (15\%). Con una contribución de 5\% al total de la década, se encuentra Brasil; Indonesia, por su parte, participa con $2 \%$ por ciento, y México con $1 \%$.

Haciendo una comparación del principio con el final de la década, podemos ver que la producción creció con relativa mayor proporción en los países no desarrollados que en los desarrollados; prueba de ello es que en 1990 los países desarrollados participaron en la producción total de este grupo con $93.3 \%$, mientras que en 2000 su contribución bajó a 91.4\%. Esto explica que el promedio anual de crecimiento de Myanmar (23.8\%), Indonesia (19\%), Brasil (5.4\%) y México (3.5\%) sea superior que el de los países desarrollados. Lo anterior denota que en las industrias consolidadas en el mercado internacional, como las de los países desarrollados de este grupo, los volúmenes producidos son tan grandes que sólo se incrementan acorde al crecimiento de la demanda mundial; mientras que en los últimos países, aun cuando su producción es relativamente baja (aceptantes de precios), se empieza a invertir en este tipo 
de industrias, dando por resultado una producción mayor (para el mismo país). Sin embargo, este fenómeno no ocurre con otros países de similar producción, como Costa Rica y Papúa Nueva Guinea, ya que en el primero su crecimiento promedio anual descendió $0.1 \%$, mientras que en el segundo la producción es nula.

Que la concentración de $91 \%$ de la producción de bienes madereros con valor agregado se dé en Estados Unidos, Canadá y Japón, está relacionado con uno de los fundamentos de la teoría de Immanuel Wallerstein, quien afirma que "las tareas ocupacionales que requieren de mayor nivel de cualificación y una mayor capitalización quedan reservadas para las áreas de mayor rango", no porque tenga que ser así sino porque estos países han alcanzado un grado de desarrollo económico que les permite invertir en investigaciones científicas, lo que conduce a desarrollar tecnología de punta, que hace eficiente y optimiza la producción forestal, al tiempo que los convierte en pioneros de estos productos. ${ }^{44}$

Brasil es otra muestra exacta de los supuestos de la teoría del sistema mundo capitalista y de lo afirmado por Samuelson. Es decir, como país semiperiférico tiene características tanto de los países del centro como de los de la periferia. En este sentido, el país brasileño posee abundancia forestal: si bien no carece de inversión industrial en este ramo, tampoco cuenta con la capacidad estructural de los países del centro, lo que se ve reflejado en los relativamente medianos volúmenes de producción.

Costa Rica (país semiperiférico), por sus relativamente pequeños volúmenes de producción, contiene características de periferia. Mientras que Indonesia (país periférico), por su cantidad de producción, tiene elementos de la semiperiferia.

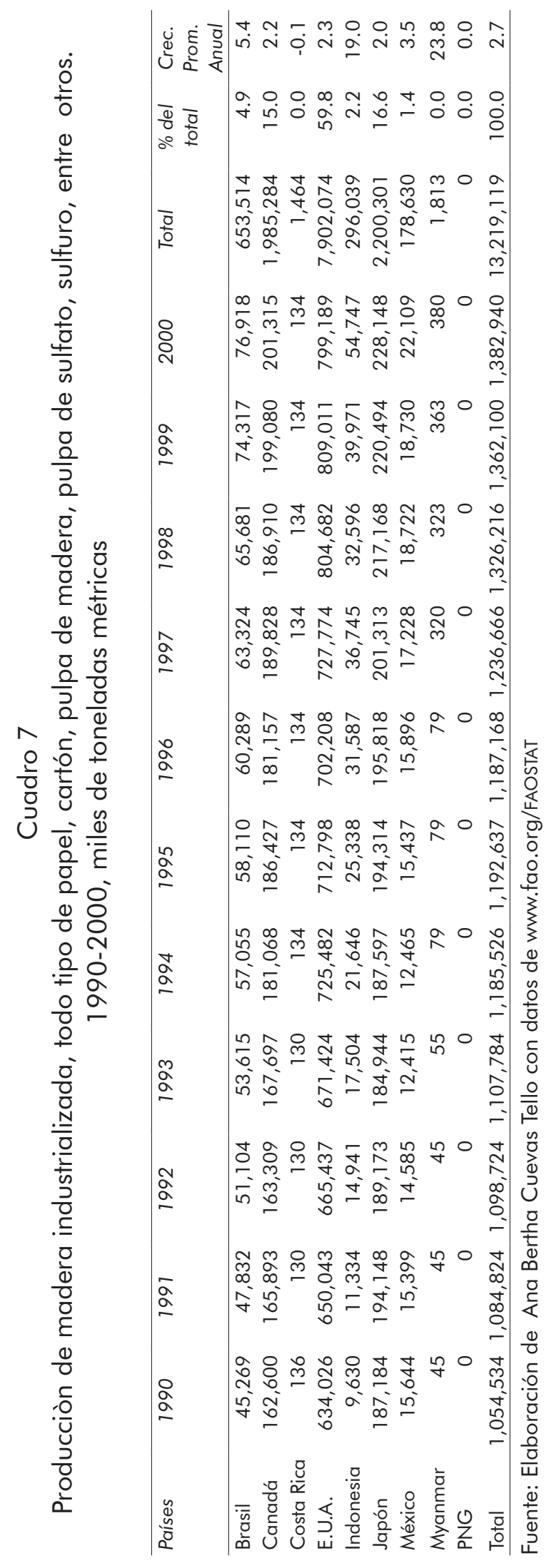

MÉXICO YLACUENCADEL PACÍFICO vol. 9, núm. 27 / enero-diciembre de 2006 
Aun cuando Papúa Nueva Guinea ${ }^{45}$ posee una extensión territorial y un grado de desarrollo económico similar al de Myanmar, no cuenta con este tipo de industria. Este hecho tal vez es el resultado de la ley de inversión que se promulgó en Myanmar en los años noventa. Cabe destacar que si Myanmar presenta, en términos absolutos, mayor proporción de mercancía en los dos tipos de industrias, también le lleva ventaja en cuanto a la tasa de deforestación se refiere, recordemos que la tasa promedio anual de deforestación en la década de los años noventa fue de $1.4 \%$, mientras que en Papúa Nueva Guinea no llegó a 0.5\%.

\section{Cuadro 8}

Producción de bienes madereros, 1990-2000, cifras acumuladas

\begin{tabular}{lrrrr}
\hline Países & $\begin{array}{c}\text { Producción } \\
\text { de la } \\
\text { industria 1 }\end{array}$ & \multicolumn{3}{c}{$\begin{array}{c}\text { Producción } \\
\text { de la } \\
\text { industria 2 }\end{array}$} \\
\cline { 2 - 5 } & $\begin{array}{c}\text { Miles de } \\
\text { metros } \\
\text { cúbicos }\end{array}$ & $\begin{array}{c}\text { \% del } \\
\text { total }\end{array}$ & $\begin{array}{c}\text { Miles de } \\
\text { toneladas } \\
\text { metricas }\end{array}$ & $\begin{array}{c}\% \text { del } \\
\text { total }\end{array}$ \\
\hline Brasil & 11784797 & 16 & 653514 & 4.9 \\
Canadá & 13540252 & 18.4 & 1985284 & 15 \\
Costa Rica & 266100 & 0.4 & 1464 & 0 \\
E.U.A & 34002448 & 46.3 & 7902074 & 59.8 \\
Indonesia & 7722641 & 10.5 & 296039 & 2.2 \\
Japón & 2336305 & 3.2 & 2200301 & 16.6 \\
México & 2126414 & 2.9 & 178630 & 1.4 \\
Myanmar & 1254989 & 1.7 & 1813 & 0 \\
PNG & 444412 & 0.6 & 0 & 0 \\
Total & 73478358 & 100 & 13219119 & 100 \\
\hline
\end{tabular}

Fuente: Elaboración de Ana Bertha Cuevas Tello con datos de www.fao.org/FAOSTAT

Evidentemente, la producción de estas dos industrias no se puede comparar, por contar cada una con niveles de medición muy diferentes. En el cuadro 8 se muestra el porcentaje de participación de los países en cada una de las industrias, a la vez que se destacan los puntos importantes del apartado. En la industria titulada con el número 1, la producción se concentra en cuatro países (Estados Unidos, Canadá, Brasil e Indonesia) de diferente nivel de desarrollo económico, mientras que el resto de las naciones contribuyen, aunque algunos en mayor medida que otro, con $8.7 \%$.

En cambio en la industria 2, aunque se puede decir que $91.5 \%$ de la producción se concentra en los tres países del centro (Estados Unidos, Canadá y Japón), en realidad la economía anglosajona abarca la mayor parte de ella (60\%); el resto — con excepción de Papúa Nueva Guinea-contribuye con $8.5 \%$. Así, aunque la producción de la industria 2 no es exclusiva de los países desarrollados, los mayores volúmenes de estos bienes se producen allí; mientras que para ser competitivo en la industria 1, uno de los requisitos es poseer suficiente extensión forestal, debido a que no se requieren de grandes cantidades de inversión. Resultado que concuerda con la teoría del sistema mundo capitalista.

\section{Comercio internacional de los recursos forestales}

Aunque en proporción del comercio total mundial de bienes y servicios los productos forestales sólo representan alrededor de $3 \%$, las cifras alcanzadas durante los años noventa fueron en aumento. Dentro de nuestro conjunto de países tenemos algunos de los principales comercializadores del mundo: Estados Unidos, Canadá y Japón.

El hecho de que los recursos forestales tengan propiedades tanto esenciales, que generan externalidades positivas (el mal uso de los bosques provoca externalidades negativas), como privadas (con utilidades monetarias), provoca a nivel mundial un interesante conflicto entre los defensores del medio ambiente y los protectores del comercio, veamos por qué. 
Debate sobre el comercio, el medio ambiente y la situación de los recursos forestales

La relación entre el comercio y el medio ambiente es, sin duda alguna, un elemento central en el esfuerzo para promover el "desarrollo sostenible", según se concibió en la Cumbre de la Tierra, en Río de Janeiro, en 1992. Una política ambiental comercial es una tarea compleja que involucra a dos sectores principales: los defensores del medio ambiente y los defensores del libre comercio. Para los primeros "la liberalización comercial parece aumentar la contaminación y disminuir la soberanía en materia de regulación, una fuerza contraria a la protección ambiental debido a la obsesión de generar más empleos y beneficios económicos". Los últimos perciben la agenda ambiental con bastante recelo, debido a que "temen que surjan nuevas maneras de proteccionismo comercial". ${ }^{46}$

En efecto, los expertos en política comercial reconocen la importancia de proteger el medio ambiente y están preocupados por mantener la integridad del sistema internacional del comercio, por lo que han reaccionado de manera defensiva a los ataques de los ambientalistas, a quienes perciben como lobos proteccionistas disfrazados de "ovejas verdes". ${ }^{47}$

El problema central en este conflicto es que los ambientalistas sustentan que la liberalización comercial conduce al establecimiento de normas, leyes y regulaciones ambientales menos estrictas. Por lo que exigen que dentro de las negociaciones comerciales se consideren normas, leyes y regulaciones que garanticen la preservación de los recursos naturales. Los defensores del libre comercio ven estas medidas como ineficaces en tres principales sentidos: a) es un mecanismo ineficiente que impide a los países aprovechar sus ventajas compa- rativas; b) son obstáculos al comercio; c) surge la sensación de que los argumentos ecológicos son utilizados para proteger una determinada industria nacional de la competencia de las importaciones. ${ }^{48}$

Pero el conflicto no termina allí. Entre los países del norte y del sur (centro-periferia) existe un debate activo relacionado con el comercio y el medio ambiente. Los países desarrollados acusan a los países menos desarrollados de tener precios más bajos por no incluir medidas de protección al ambiente. Los países del sur arguyen que los países del norte, en su proceso de desarrollo, también emplearon medidas poco favorables a la conservación ambiental ${ }^{49}$ acusan, además, a los países del centro de establecer sus industrias contaminantes en otros países. Estos mismos países industrializados (en general) se quejan de que las economías en desarrollo emplean regulaciones ambientales significativamente menos estrictas (y menos costosas), que son receptores de ventajas injustas para la competitividad tanto en los productos exportados, como atrayente de IED.

En este sentido, los países desarrollados han impuesto al interior de su territorio políticas, normas y reglamentos que de alguna manera fungen como instrumentos de política comercial, lo que afecta directamente las importaciones. Sobre esto, los países en desarrollo han expresado su inquietud en el sentido de que sus exportaciones podrían ver restringido su acceso a los mercados, o bien que podrían incurrir en altos costos por concepto de ajuste, a fin de cumplir con las regulaciones del producto que pretenden enfrentar los problemas ambientales en los países industrializados. ${ }^{50}$

El conflicto entre los defensores del libre comercio y los protectores del medio ambiente es sin duda uno de los grandes desafíos del siglo XXI. Sin embargo, debe-

MÉXICO YLACUENCADELPACÍFICO vol. 9, núm. 27 / enero-diciembre de 2006 
mos recordar que la importancia de llegar a un acuerdo se debe a que "la Tierra no tiene una capacidad ilimitada de absorción de la contaminación". En cuanto a los recursos forestales, se estima que la deforestación ha llegado demasiado lejos como para ser reversible. Incluso si fuera reversible, se tardaría muchas generaciones en restituir los bosques y las selvas perdidas. ${ }^{51}$

Un ejemplo citado por la Comisión Económica para América Latina (CEPAL) ilustrará mejor el conflicto particular de los recursos forestales y el comercio de este bien:

\section{[...] un país con grandes áreas de bosque posee- ría ventajas comparativas en la producción y exportación de productos forestales. Sin embar- go, también tendría ventaja comparativa en la exportación de servicios de absorción de dióxido de carbono o en biodiversidad. Pero como estos servicios no son considerados por el sistema de precios de mercado, éste tampoco traducirá ese beneficio privado, subestimando de esa manera el verdadero valor de este recurso natural. ${ }^{52}$}

Hay otro punto de vista, que difiere un poco de la postura tanto de los ambientalistas como de los defensores del comercio. Éste sostiene que el crecimiento del comercio contribuye al aumento de la riqueza y la difusión tecnológica, lo que al mismo tiempo genera la posibilidad de que la sociedad proteja sus recursos naturales. Sin embargo, considera que "el comercio irrestricto puede ser dañino a su medio ambiente, especialmente en los países cuyas políticas ambientales son débiles o inexistentes". ${ }^{53}$ Esto porque el comercio se rige bajo la ley de la oferta y la demanda, sin importar el daño o no al medio ambiente, por lo que desde las políticas naciones es donde se le tiene que poner límite al comercio y dar protección al medio ambiente.

Por lo anterior, en este trabajo se manejará la versión de que el daño ambiental, y en particular de los recursos forestales, se encuentra determinado más por la ausencia o debilidad de las políticas ambientales internas, que por efecto mismo del comercio. Iniciamos, así, el análisis de este apartado. El objetivo es observar el desarrollo, a lo largo de diez años, del comercio internacional forestal de estos países, con la intención tanto de conocer la importancia de su mercado y el ciclo productivo, como de verificar de dónde satisfacen los habitantes -y las industrias - la demanda de este bien. Al mismo tiempo, se procurará delimitar el papel del comercio internacional en la deforestación de la superficie forestal. Dentro de las importaciones y las exportaciones se harán las dos distinciones establecidas en las industrias nacionales expuestas en el apartado anterior.

\section{Comercio forestal internacional de los nueve países}

El comercio internacional (exportaciones más importaciones) de productos forestales de los nueve países seleccionados, tuvo el siguiente comportamiento durante la década de los noventa: 1) el comercio total fue de 4'073,751 millones de dólares; 2) la tendencia del comercio forestal fue positiva, con un pequeño declive que inició en 1996 y alcanzó su nivel mínimo en 1998 y se recuperó en los dos años posteriores; 3) 
en general estos países son exportadores, debido a que presentaron un saldo positivo de 430,072 millones de dólares.

Los mayores exportadores del grupo son Canadá, Estados Unidos e Indonesia, ya que juntos acaparan más de $88 \%$ del total de los bienes exportados. Los grandes importadores son Estados Unidos y Japón, debido a que en conjunto alcanzaron casi $84 \%$ de las importaciones realizadas durante este periodo. Los países que podemos considerar con cifras comerciales relativamente medianas son Indonesia y Brasil; sin embargo, podemos ver que aun cuando Indonesia es un país de la periferia (Brasil, de la semiperiferia) y conserva menor superficie forestal que Brasil, mantiene un comercio más eficiente que este último. Los que tienen menores cantidades comerciadas son Costa Rica, Myanmar,
Papúa Nueva Guinea y México.

Los países que durante estos diez años resultaron con saldo negativo (déficit) son Japón, Estados Unidos, México y Costa Rica. De las cantidades importadas de estos países sobresalen Costa Rica, Japón y México, porque en proporción a su comercio total, las compras al exterior representaron más de $87 \%$, mientras que las importaciones de Estados Unidos alcanzan 53\% del total de su comercio.

Los países que representaron superávit en su balanza comercial forestal fueron $\mathrm{Ca}$ nadá (nación cuyas exportaciones acaparan casi la mitad de las exportaciones totales del grupo), Brasil, Indonesia, Myanmar y Papúa Nueva Guinea. De estos últimos, las exportaciones representaron $97 \%$ y $98 \%$, respectivamente, de su comercio forestal total.

\section{Gráfica 3}

Comercio Internacional de productos forestales de los nueve países $(M+X)$ :

1990-2000, cifras acumuladas

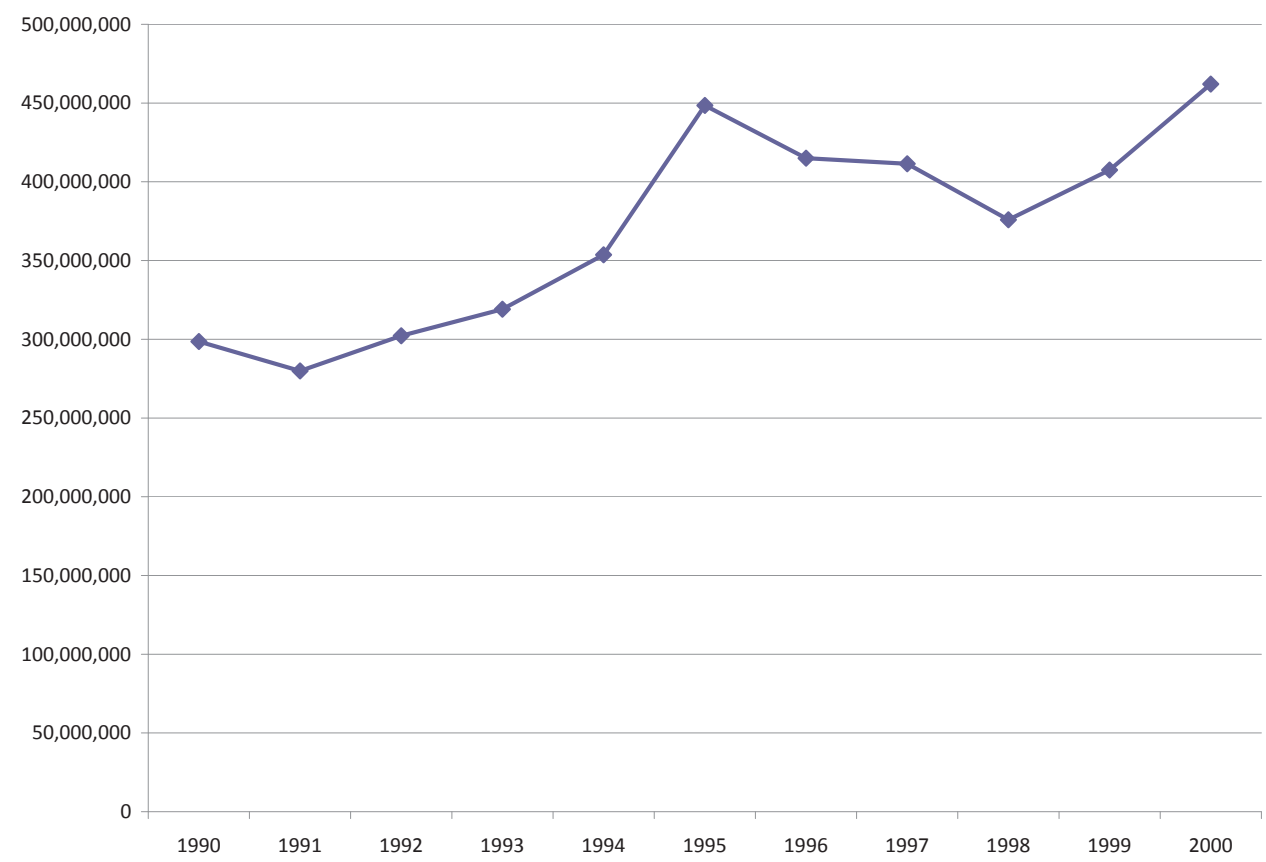

Fuente: Elaboración de Ana Bertha Cuevas Tello con datos de www.fao.org/FAOSTAT 
Análisis

\section{Cuadro 9}

Comercio total de produtos forestales de los nueve países

cifras acumuladas, miles de dólares (1990-2000)

\begin{tabular}{lrrrr}
\hline Países & Exportaciones & \multicolumn{1}{c}{ Importaciones } & \multicolumn{1}{c}{ Total } & \multicolumn{1}{c}{ Saldo (X-M) } \\
\hline Brasil & $130,591,818$ & $36,325,078$ & $166,916,896$ & $94,266,740$ \\
Canadá & $1,032,771,105$ & $139,489,592$ & $1,172,260,697$ & $893,281,513$ \\
Costa Rica & 613,683 & $7,621,426$ & $8,235,109$ & $-7,007,743$ \\
E.U.A & $778,158,559$ & $876,137,280$ & $1,654,295,839$ & $-97,978,721$ \\
Indonesia & $182,123,889$ & $44,317,803$ & $226,441,692$ & $137,806,086$ \\
Japón & $87,668,365$ & $647,955,249$ & $735,623,614$ & $-560,286,884$ \\
México & $10,599,829$ & $69,255,840$ & $79,855,669$ & $-58,656,011$ \\
Myanmar & $11,842,678$ & 412,373 & $12,255,051$ & $11,430,305$ \\
PNG & $17,542,140$ & 324,505 & $17,866,645$ & $17,217,635$ \\
Total & $2,251,912,066$ & $1,821,839,146$ & $4,073,751,212$ & $430,072,920$ \\
\hline
\end{tabular}

Fuente: Elaboración de Ana Bertha Cuevas Tello con datos de www.fao.org/faostat

Hasta aquí hemos revisado de manera general el comportamiento del comercio forestal internacional de los países, pero para darle mayor peso al apartado es necesario revisar de manera separada el comercio internacional forestal por industria; es decir, las compras y ventas de productos madereros con poco valor agregado y los bienes forestales con un alto grado de capital tecnológico. Empecemos con el comercio internacional del primer grupo de productos.

\section{Comercio internacional de productos} con poco valor agregado (industria 1)

La balanza comercial de este grupo de países es superavitaria. El total del comercio internacional de madera aserrada, durante los diez años, fue de 2'018,972 millones de dólares. Las exportaciones de los países de la periferia - Indonesia, Myanmar y Papúa Nueva Guinea - participaron en el total de este rubro con $13 \%, 1.7 \%$ y $1.5 \%$, respectivamente. Las exportaciones de Indonesia representaron en su comercio total 92.3\%; en Myanmar desempeñaron 99.1\%; en Papúa Nueva Guinea, 99.6 puntos por- centuales. Es decir, las compras al exterior de este tipo de productos forestales son casi nulas en estos países, lo que los cataloga como exportadores netos de los productos forestales de la industria 1.

Japón, ${ }^{54}$ México y Costa Rica ${ }^{55}$ son considerados importadores netos ${ }^{56}$ de madera aserrada, por tener la proporción de importaciones mayor $80 \%$, en relación con su comercio forestal internacional. Aunque las importaciones de Estados Unidos representan poco más de $50 \%$, y muestra una balanza deficitaria, no se le considera como importador neto porque sus intercambios comerciales son relativamente equitativos; sin embargo, en cifras absolutas es el segundo importador del grupo (después de Japón).

Canadá y Brasil destacan por ser exportadores netos de madera aserrada, ya que las ventas al exterior representan alrededor de $88 \%$ de su comercio total. Sobresale Canadá por ser el primer exportador y segundo mayor comerciante $(\mathrm{X}+\mathrm{M})$ del grupo (y del mundo, después de Estados Unidos), cuando cuenta con poco menos de la mitad de la superficie forestal de Brasil.

En relación con las tendencias del co- 
Análisis comparativo del manejo forestal de algunos países de Asia y América: 1990-2000

Cuadro 10

Comercio total de productos forestales de madera aserrada, cifras acumuladas: 1990-

2000

\begin{tabular}{lrrrr}
\hline Países & Exportaciones & \multicolumn{1}{c}{ Importaciones } & \multicolumn{1}{c}{ Total } & \multicolumn{1}{c}{ Saldo (X-M) } \\
\hline Brasil & $44,620,134$ & $8,749,891$ & $53,370,025$ & $35,870,243$ \\
Canadá & $454,609,737$ & $61,351,100$ & $515,960,837$ & $393,258,637$ \\
Costa Rica & 421,525 & $1,776,376$ & $2,197,901$ & $-1,354,851$ \\
E.U.A & $338,177,687$ & $397,009,293$ & $735,186,980$ & $-58,831,606$ \\
Indonesia & $135,117,314$ & $11,635,821$ & $146,753,135$ & $123,481,493$ \\
Japón & $19,294,989$ & $487,249,608$ & $506,544,597$ & $-467,954,619$ \\
México & $5,574,412$ & $23,299,261$ & $28,873,673$ & $-17,724,849$ \\
Myanmar & $11,841,286$ & 117,022 & $11,958,308$ & $11,724,264$ \\
PNG & $17,542,059$ & 84,648 & $17,626,707$ & $17,457,411$ \\
Total & $1,027,199,143$ & $991,273,020$ & $2,018,472,163$ & $35,926,123$ \\
\hline
\end{tabular}

Fuente: Elaboración de Ana Bertha Cuevas Tello con datos de www.fao.org/FAOSTAT

mercio de productos forestales primarios, podemos observar durante la década de los noventa que son positivas, debido a que las importaciones totales mostraron un crecimiento promedio anual de $3 \%$, mientras que las exportaciones aumentaron un punto porcentual más (4\%). Los países donde el crecimiento de la capacidad de importación fue mayor a dos dígitos son: Myanmar (16\%), Brasil (16\%), México (15\%), Costa Rica (13\%) e Indonesia (12\%). Las importaciones del resto sólo aumentaron en promedio 7\% anual; las compras de Japón al exterior disminuyeron aproximadamente 1 por ciento anual. En general, en este tipo de comercio hasta 1996 las importaciones mostraron una tendencia positiva, la cual disminuyó considerablemente en 1998, para después recuperarse de manera paulatina (este fenómeno está relacionado con la crisis asiática).

Las exportaciones crecieron en promedio un punto porcentual más que las importaciones. Los países que mayor crecimiento promedio anual mostraron fueron Brasil (9\%), Costa Rica (8\%), Papúa Nueva Guinea (7\%) y Canadá (6\%). Estados Unidos no presentó crecimiento y las exportaciones de Japón sólo aumentaron $2 \%$. Al mismo tiempo, el crecimiento anual de las exportaciones de México, Myanmar e Indonesia osciló entre 3\% y 4\%, respectivamente. $\mathrm{Al}$ igual que las importaciones, el crecimiento de las exportaciones mostró un declive posterior a 1996, el cual recupera cifras para 2000.

Comercio internacional de productos madereros que requieren mayor grado de inversión (industria 2)

La balanza comercial donde se registran las compras y las ventas al exterior de todo tipo de papel, pulpa, triplay, entre otros, es superavitaria para los países de la muestra considerados en conjunto. Las exportaciones, desde una perspectiva grupal, representan 60\% del comercio total. Canadá y Estados Unidos son los países que mayores cantidades exportaron, ya que juntos se adjudicaron $83 \%$ del total. Las exportaciones de Indonesia, Myanmar y Papúa Nueva Guinea 59\%, 0.5\% y 0.3\%, respectivamente, del total de los productos comerciales, lo que indica que a excepción de Indonesia estos dos países son considerados importadores netos de este tipo de mercancías.

Estados Unidos y Japón presentaron durante este periodo un déficit en su ba-

MÉXICO YLACUENCADELPACÍFICO 101 

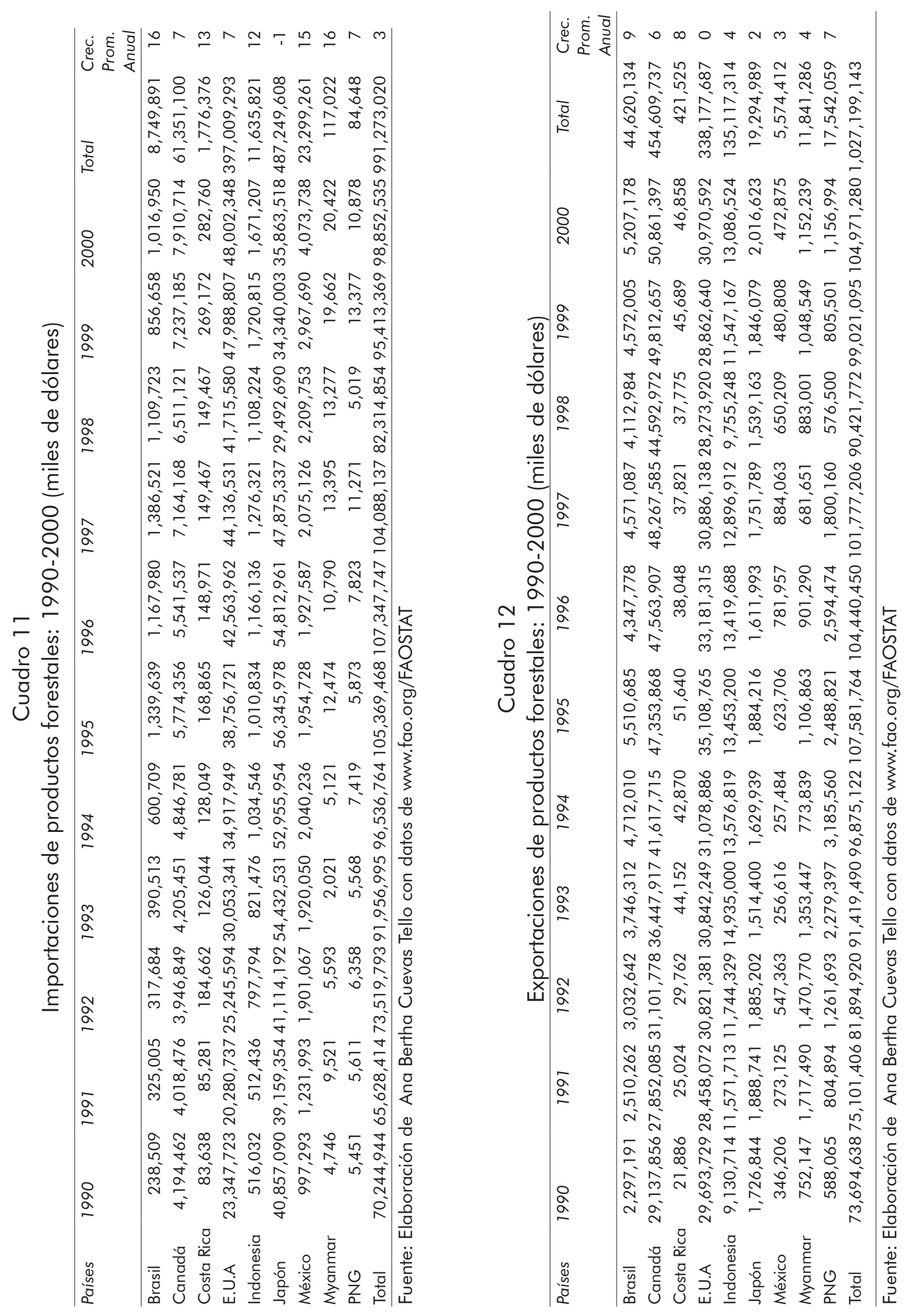

$102 \begin{aligned} & \text { MÉXICO YLACUENCADEL PACÍFICO } \\ & \text { vol. 9, núm. } 27 \text { / enero - diciembre de } 2006\end{aligned}$ 
Cuadro 13

Balanza comercial forestal, 1990-2000, miles de dólares (cifras acumuladas)

\begin{tabular}{lllll}
\hline Países & Importaciones & Exportaciones & Total & Saldos \\
\hline Brasil & $27,575,187$ & $85,971,684$ & $113,546,871$ & $58,396,497$ \\
Canadá & $78,138,492$ & $578,161,368$ & $656,299,860$ & $500,022,876$ \\
Costa Rica & $5,845,050$ & 192,158 & $6,037,208$ & $-5,652,892$ \\
E.U.A & $479,127,987$ & $439,980,872$ & $919,108,859$ & $-39,147,115$ \\
Indonesia & $32,681,982$ & $47,006,575$ & $79,688,557$ & $14,324,593$ \\
Japón & $160,705,641$ & $68,373,376$ & $229,079,017$ & $-92,332,265$ \\
México & $45,956,579$ & $5,025,417$ & $50,981,996$ & $-40,931,162$ \\
Myanmar & 295,351 & 1,392 & 296,743 & $-293,959$ \\
PNG & 239,857 & 81 & 239,938 & $-239,776$ \\
Total & $830,566,126$ & $1,224,712,923$ & $2,055,279,049$ & $394,146,797$ \\
\hline
\end{tabular}

Fuente: Elaboración de Ana Bertha Cuevas Tello con datos de www.fao.org/FAOSTAT

lanza comercial. Las importaciones para el primero representan más de la mitad de su comercio; para Japón abarca 70\%. Ello nos da la pauta para concluir que estos países son los grandes consumidores de este tipo de bienes en el mundo. México y Costa Rica también dependen del exterior para garantizar la demanda de los consumidores nacionales de este tipo de productos; para el primero, las importaciones representan 90\% de su comercio; para Costa Rica, 97\%. Para Brasil (economía semiperiférica como los otros dos) sólo 24\%. El comercio de este último, aunque relativamente mediano, es superavitario.

Tanto las importaciones como las exportaciones de este tipo de mercancías para el grupo de países crecieron en promedio $5 \%$ anual. Los países que mantuvieron una tendencia positiva mayor a dos dígitos, en lo que a compras al exterior se refiere, fueron Brasil (18\%), Myanmar (17\%), México (15\%), Costa Rica (14\%) e Indonesia (12\%). Para Canadá, Estados Unidos y Papúa Nueva Guinea, el crecimiento fue de $7 \%$ y $5 \%$, respectivamente. Mientras que las importaciones forestales de Japón crecieron en promedio sólo $2 \%$. Como se puede ver, para ningún país las importaciones se mantuvieron sin cambios o en retroceso.

En cuanto al crecimiento promedio anual de las exportaciones en la década de los noventa, en todos los países fue positivo, excluyendo a Myanmar y Papúa Nueva Guinea, por ser sus ventas al exterior muy irregulares. La nación que presentó mayor crecimiento fue Indonesia (29\%); le siguen México (10\%) y Brasil (7\%). El resto de las economías se incrementaron entre $2 \%$ y $5 \%$.

Como se puede ver, la evolución de las exportaciones y las importaciones mostró altas y bajas; sin embargo, resulta evidente que la tendencia es positiva. Para los mayores exportadores (Estados Unidos y Canadá) los años que más producción colocaron al exterior fueron 1995 y 2000. Es interesante observar que mientras el comercio de productos de la industria 1 redujo sus cantidades comerciadas en los mismos años de la crisis asiática, la comercialización de la mercancía de la industria 2 , aunque presentó retrocesos en dichos años, tuvo una recuperación más rápida.

\section{Conclusión}

Tras los lineamientos de la teoría de sistema mundo capitalista, los países de la periferia proveen de madera aserrada (insumo) a los países del centro. Estos últimos, con su avanzado desarrollo productivo, indus- 

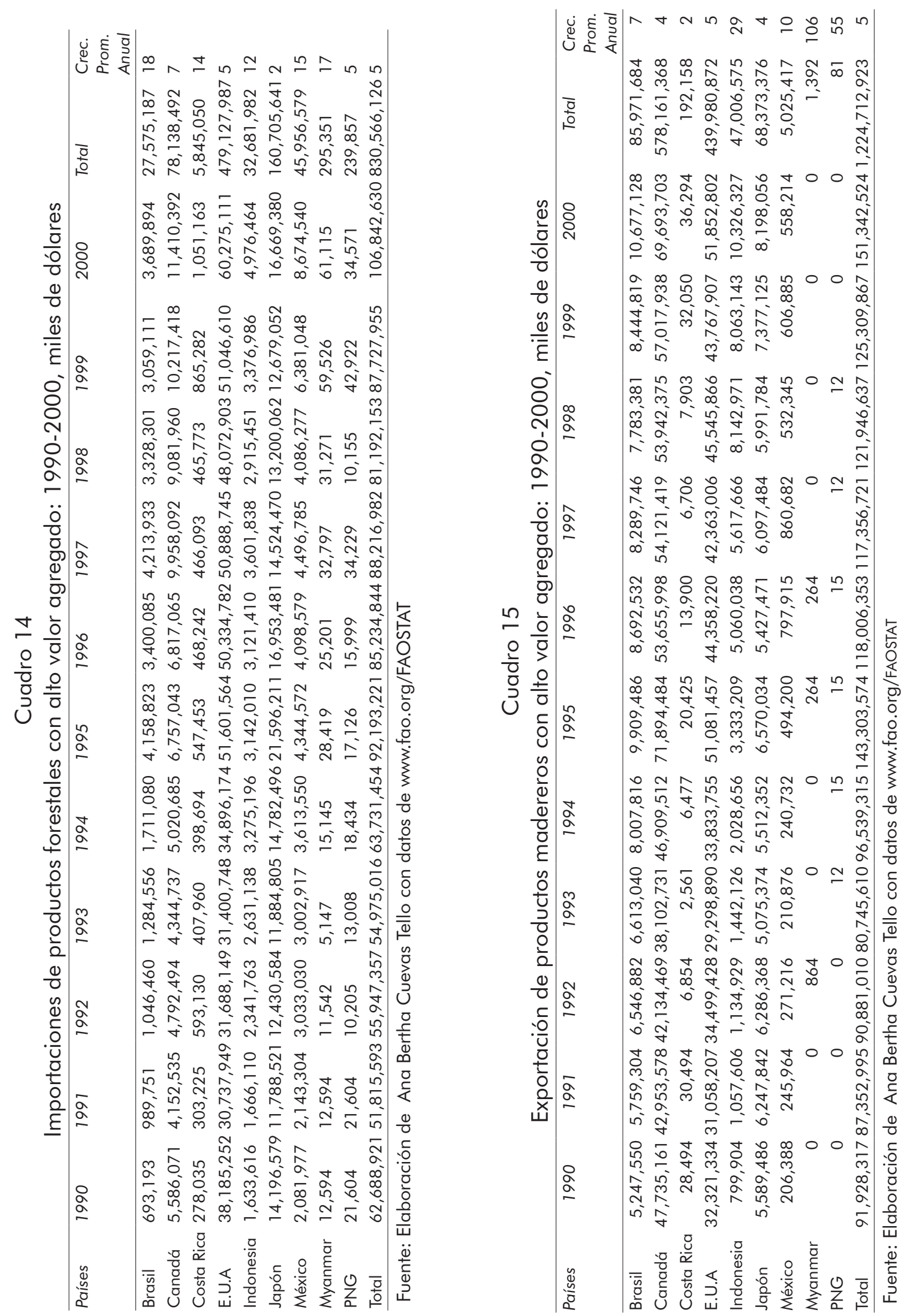

$104 \begin{aligned} & \text { MÉXICO Y LACUENCADEL PACÍFICO } \\ & \text { vol. 9, núm. } 27 \text { / enero - diciembre de } 2006\end{aligned}$ 
trializan la madera produciendo bienes con alto valor agregado, lo que implica mayores beneficios económicos. En este sentido, los países periféricos están acabando los recursos forestales con tal de movilizar la economía doméstica, debido a que este sector económico tiene contribuciones importantes en el PIB, recibiendo a cambio un precio relativamente bajo por su venta, al mismo tiempo que provocan detrimento y disminución de su área forestal. En posición contraria, los países del centro, con la importación de insumos madereros y tras elaboración avanzada, colocan sus productos (ya manufacturados) en todos los rincones de la tierra, lo que les reditúa beneficios económicos, un mejor nivel de vida de sus habitantes y la protección de sus recursos forestales.

El sector agrícola y el forestal tiene un peso relativamente importante en el PIB de los países de la periferia, y decrece la relevancia conforme se llega al centro. Los países de la periferia aquí analizados tienen en común la deforestación de los bosques y el crecimiento de la superficie agrícola (en Indonesia, a partir de 1996); sin embargo, la disminución de la primera no es absorbida en su totalidad por la segunda, hecho que puede deberse a: 1 . Las altas proporciones de ciudadanos que habitan en la zona rural y el crecimiento de las relativas altas tasas demográficas, lo que indudablemente ejerce presión en la ampliación de la mancha habitacional; 2. En el caso de Myanmar y Papúa Nueva Guinea por su bajo nivel de capital y cualificación de la fuerza laboral, que dificultan el manejo sustentable de los bosques, y la renovación de éstos a través de plantaciones funcionales (estas tierras se quedan sin fines específicos).

Indonesia sí tiene un manejo avanzado de plantaciones, pero son insuficientes para la acelerada tasa de deforestación.
Otra característica que tienen en común estas economías, a excepción de Indonesia, es que la capacidad de su capital productivo sólo les da para producir bienes de la industria 1. Aunque el fuerte de Indonesia es producir elementos de la industria 1, también fabrica cantidades relativamente importantes de la industria 2. Estos tres países son en esencia exportadores netos de productos forestales y, excepto Indonesia, son importadores netos de productos con valor agregado. En cuanto a su producción y comercio, Indonesia tiene características de semiperiferia.

En las economías de los países del centro, tanto el valor agregado del sector agrícola como el forestal tienen una participación relativamente baja en el PIB. Como países desarrollados que son, poseen muchas similitudes en su manejo: sin embargo, también existen distinciones. En estos países la superficie agrícola disminuye, mientras que la forestal aumenta (en Canadá permaneció sin cambios), mas no en las mismas proporciones, por lo que si bien Estados Unidos y Japón cuentan con áreas de plantaciones funcionales, éstas no absorben el total de las tierras arables que dejaron de utilizar para esta actividad (es posible que se le esté dando uso urbano). Estos tres países son los principales productores-comercializadores de productos forestales en el mundo, lo que habla de su capacidad productiva basada en la tecnología de punta. Canadá queda fuera de las características de la teoría del sistema mundo capitalista, al ser mínimas las cantidades importadas de productos forestales primarios. En Japón y Estados Unidos este elemento sí se cumple. Cabe aclarar que EU es el segundo mayor exportador en el mundo de este tipo de bien, a diferencia de Japón, el cual es importador neto de los dos tipos de productos. Es decir, ambos satisfacen su consumo maderero del

MÉXICO YLACUENCADEL PACÍFICO 105
vol. 9, núm. 27 / enero-diciembre de 2006100 
exterior, mas Estados Unidos lo industrializa y coloca una parte en el exterior.

Las economías semiperiféricas tienen características de ambos polos, por lo tanto, tal es su peculiaridad. En estos tres países la agricultura tiene una importancia relativamente destacable en la economía, al emplear a poco más de $20 \%$ de la población y porque su contribución al PIB es de $4 \%$, $7 \%$ y $9 \%$, respectivamente. En los tres aumentó las superficie agrícola y disminuyó la forestal; para Brasil casi en las mismas proporciones (siendo superior lo deforestado) y para los otros dos hay un espacio considerable, que por el crecimiento de la población podría emplearse con fines habitacionales. Los volúmenes de producción de Costa Rica de la industria 1 son inferiores a la de los países de la periferia, mas su espacio forestal es también menor; sin embargo, en la industria 2 su producción es comparable con la de Myanmar y superior a la de Papúa Nueva Guinea — que no tiene producción-. En cuanto al comercio, esta economía tiene elementos de ambos lados en el sentido de importar casi la totalidad de su consumo interno de productos forestales primarios y los de valor agregado, caso similar al de México. Este último país tiene una producción inferior a Indonesia en las dos industrias.

La producción de Brasil, a pesar de ser el país con la mayor superficie forestal de la muestra y el segundo a nivel mundial, es relativamente inferior a Estados Unidos y Canadá; ello es consecuencia del capital productivo, que no le permite alcanzar cifras más altas. Este país es exportador neto en ambos productos.

En suma, la situación real del manejo forestal tiene muchos matices, aunque en general, los países cuentan con las características otorgadas por la teoría del sistema mundo capitalista. Al interior de los países hay hechos y circunstancias que los hacen manejar de manera muy particular los bosques. Por lo tanto, resulta oportuno tratar de hacer una clasificación, considerando los elementos y limitaciones de este trabajo, de buen o mal manejo de los recursos de estos países.

Así, sólo tres naciones tuvieron, durante los años noventa, buen manejo de sus recursos forestales. El país con el mejor manejo del grupo es Canadá. Esta economía aunque no aumentó su cubierta forestal, tampoco la disminuyó. Su capacidad productiva es muy eficiente, lo que se refleja dentro del comercio internacional (exportador neto).

Japón y Estados Unidos también tienen un buen manejo forestal, porque no sólo no disminuyeron el área forestal sino que la aumentaron a través de plantaciones. Estos países tienen grandes volúmenes de producción y figuran entre los mayores comerciantes de productos forestales del mundo. Sin embargo, ambos países presentaron déficit en su balanza comercial, especialmente Japón, considerado como importador neto. Lo anterior nos lleva a concluir que estos países mantienen buen manejo de sus bosques a costa de acabarse los recursos de sus socios comerciales. Lo anterior perjudica a nivel global, pues recordemos que los bosques son bienes públicos mundiales. No obstante, como este análisis se realiza desde plano doméstico, se puede decir que estos países hacen buen uso de sus recursos forestales.

De los seis países con mal manejo forestal, Myanmar es el que más rápidamente se está acabando sus bosques, ya que tuvo una deforestación promedio anual de 1.4\%. Indonesia es la segunda economía con mal manejo forestal por disminuir año con año (en promedio) 1.2\% su superficie forestal. Indudablemente (para la capacidad productiva con la que cuenta) este país es gran productor y exportador de productos 
forestales, pero evidentemente a costa de disminuir su extensión forestal.

México es el tercer país con peor manejo forestal por disminuir en promedio sus bosques $1.1 \%$. Su capacidad productiva es relativamente mala, lo que genera la necesidad de satisfacer su consumo del exterior (es importador neto de ambas industrias). Costa Rica es el cuarto país con deficiente manejo forestal, ya que si bien su promedio anual de deforestación no alcanza 1\% (0.8\%), éste fue constante, lo que llevó al país a perder en la década de los noventa $1,580 \mathrm{~km}^{2}$ de área forestal. Su capacidad productiva es baja, y esto lo convierte en importador neto.

Papúa Nueva Guinea y Brasil tienen el mismo promedio de deforestación, por lo que serían los dos países que salieron mejor librados dentro de la clasificación. Es necesario señalar que si bien ambos países están acabando al mismo ritmo sus respectivos bosques, en valores absolutos éstos son muy distantes. Brasil tuvo un promedio anual de deforestación de los 22264 km², mientras que Papúa Nueva Guinea deforestó en promedio $1,129 \mathrm{~km}^{2}$. Lo anterior quiere decir que Brasil causa mayores perjuicios a escala global que a nivel nacional: como bienes públicos globales que son los bosques, la deforestación de este país generó, en la última década del siglo XX, mayores perjuicios globales que los de cualquier otra economía de la selección.

A lo largo de este trabajo pudimos observar que, debido a la multifuncionalidad de los bosques, el manejo sustentable de ellos no es un asunto sencillo, pues existen una serie de intereses inherente a los recursos forestales. Si los países miembros de Naciones Unidas reformaron sus leyes forestales con fines sustentables, éstos no fueron evidentes en la mayoría de los países de la muestra.

\section{Notas al pie}

1. Evaluación de los Recursos Forestales Mundiales 2005. Disponible en: www.fao.org/forestry.

2. Samuelson, Nourdhaus, 2002: 320.

3. Fishcher, Dornbursch y Schmalensee, 1994: 491. กญฏ

4. White, 2002: 9.

5. Cook y Sachs, 1999: 458.

6. Wallerstein, 1999: 492.

7. Wallerstein, 1999: 492.

8. Wallerstein, 1999: 493.

9. China también es uno de los países con grandes superficies de bosque, pues contiene $35 \%$ más superficie forestal que Indonesia (www.fao.org/ forestry).

10. Cirelli y Schmithûsen, 2000: 2-4.

11. Se entiende por deforestación la eliminación del bosque y su sustitución por otro tipo de uso de la tierra, como la agricultura itinerante o permanente, la minera o la urbanización (FAO, 2001: 43).

12. Escalante y Aroche, 2000: 10-12.

13. Semarnap, 2000: 127-128.

14. FAO, 2001: 38.

15. Kanowski, 2000: 25.

16. FAO, 2001: 39-40.

17. Evans, 2001: 40.

18. Humphreys, 2003: 46.

19. WRM, 2003: 1 .

20. http://www.wem.org.uy/plantaciones/impactoscopia.html.

21. Messier, Bigué, Benier, 2003: 62-63.

22. FAO, 2000: 3.

23. FAO, 2001: 8-9.

24. WRM, 2003: 3.

25. Ministry of Forestry Republic of Indonesia, 1998: 8.

26. Carrere y Lohmann, 2001: 2-5.

27. Carrere y Lohmann, 2001: 8.

28. WRM, 2001: 1-3.

29. Escalante y Aroche, 2000: 30-31.

30. En el capítulo III, los artículos 28, 29 y 30 de la Ley Forestal de Costa Rica están dedicados al fomento de las plantaciones forestales y a la descripción de los incentivos para reforestar (Ley Forestal de Costa Rica).

31. Montagnini, 2003: 1.

32. Forest Department Ministry of Forestry Myanmar, 1997: 6 .

33. Keh, 2001: 49 .

34. Kasonwski, 2000: 2.

35. Messier, Bigué y Benier, 2003: 61.

36. National Forest Service PNG, 1997: 11.

37. FAO, 2003: 3.

38. Samuelson y Nordhaus, 2002: 93. 
39. http://www.fao.org/foresty/foris/webview/foresty2/index.jsp? siteld=1280\&langld $=1$.

40. http://www.fao.org/forestry/foris/webview/forestry2/index.jsp?siteld=1280\&langld=1.

41. Banco Mundial, 2002: 133.

42. Semerena y Aroche, 2000: 29.

43. Appleyard y Field, 1997: 167.

44. Wallerstein, 1999: 493.

45. En cuanto a la importancia del sector forestal entre los países, en Papúa Nueva Guinea es una de las actividades que más contribuye al Producto Interno Bruto Nacional: la producción forestal junto con las exportaciones de este recurso son el tercer sector en importancia en la economía, y al empleo debido a que se encuentran laborando dentro del ramo 7,500 personas, lo que representa aproximadamente $4 \%$ del total de los empleos formales (Nacional Forest Service PNG, 1997: 2-3).

46. Barreras a productores extranjeros para acceder al mercado reduciendo las ganancias en eficiencia de un comercio más libre, bajo el disfraz políticamente atractivo de la mejora ambiental (Esty, 2001: 16).

47. Horowitz, 1995: 14.

48. Vossenar, 1994: 17; Horowitz, 1994: 14.

49. Esty "los países desarrollados se han enriquecido a costa del medio ambiente" (2001: 23-24).

50. Veena Jha, 1994: 129; Vossenar, 1994: 19; Horowitz, 1994: 12.

51. Entre 1990 y 1995, se perdieron 56 millones de hectáreas de bosques. Esta cifra es el resultado de los 65 millones de hectáreas destruidas en los países en vías de desarrollo y los 9 millones de hectáreas reforestadas en los países desarrollados (Esty, 2001: 29-32).

52. CEPAL, 1995: 65.

53. Horowitz, 1995: 12.

54. El $96 \%$ de su comercio total forestal fueron importaciones.

55. El $81 \%$ del comercio total de México y Costa Rica son importaciones.

56. Estos dos países no sólo son los grandes importadores del grupo sino del mundo (FAO, 2003: 56).

\section{Bibliografía}

Appleyard, D. y A. Field, Economía Internacional, McGraw-Hill, España, 1997.

Banco Mundial, Informe sobre el Desarrollo mundial 2003, desarrollo sostenible en un mundo dinámico, transformación de instituciones, crecimiento y calidad de vida, Mundi-Prensa Libros, 2003, EU, Washington, DC.
Carrer, R. y L. Lohmann, Brasil el gigante de la pulpa de Eucalipto, del libro Movimiento Mundial por los Bosques Tropicales, Montevideo, Uruguay, 2001.

Cirelli, M. y Schmithûsen, "Tendencias del derecho forestal: Europa occidental", FAO, Roma, 2000, en: www.fao.or/legal.

CEPAL, "Medio ambiente y comercio internacional en América Latina", en SELA-UNCTAD, Comercio y medio ambiente, Editorial Nueva Sociedad, Venezuela, 1995.

Cook, L. y J. Sach, "Los bienes públicos regionales en la ayuda internacional", en Kaul, I, I. Grunberg y M. Stern, Bienes públicos mundiales, Oxford University Press, México, 2001.

Escalante, R. y F. Aroche, El sector forestal mexicano: paradojas de la explotación de un recurso natural, Universidad Autónoma de México, México, 2000.

Esty, D., El reto ambiental de la Organización Mundial del Comercio, Gedisa, Barcelona, España, 2001.

Evans, J., Sostenibilidad de la producción de madera en las plantaciones forestales, Department of Forestry, University of Canberra ACT, 2001.

FAO, "Situación forestal en los Estados Unidos, por la Comisión Forestal para América del Norte, 20 reunión", 2000, en: http://wwwfao.org/docrep/ meeting/X4995S.htm.

- , "Situación Forestal en los Estados Unidos de América", FAO, Roma, Italia, 2000, en: www.fao. org/forestry/fo/country.

_- Situación de los bosques del mundo, FAO, Roma, Italia, 2001.

- State of the World's Forest, FAO, Roma, Italia, 1999.

_ (2003), State of the World's Forest, FAO, Roma, Italia.

Fischer, S., R. Dornbusch y Schmalensee, Economía, McGraw-Hill, México, 1994.

Horowitz, E., "El vínculo comercio/medio ambiente", en SELA-UNCTAD, Comercio y medio ambiente, Editorial Nueva Sociedad, Venezuela, 1995.

Humphreys, D., "Life Protective or carcinogenic Challenge? Global Forest Governance under Advance Capitalism", Global Environmental Politics, mayo, The Massachusetts Institute of Technology, EU, 2003, núm. 3, pp. 2.

Kew, S., ¿̇Establecimiento de plantaciones de teca en Myanmar?, Forestry Department, Institute of Forestry Yezin, Myanmar, 1998.

Messier, C., B. Bigué y L. Benier, "Plantaciones de crecimiento rápido para la protección del ecosistema forestal de Canadá", Unasilva, Roma, Italia, 2003, vol. 54, pp. 214-215.

Ministry of Forestry Republic of Indonesia, Country Report-Indonesia, Forestry Policy and Planning Division, Rome and Regional Office for Asia and Pacific, Bangkok, 1998. 
Montagnini, F., Plantaciones forestales con especies nativas en América central, Boletín SAVIA, diciembre, 2003, en: www.fnatura.org/paginas/redlatinbosques/savia.

National Forest Service Papua Nueva Guinea, Country Report-Papua Nueva Guinea, Forestry Policy and Planning Division, Regional Office for Asia and the Pacific, Bangkok, 1997

Samuelson, P. y W. Nourdhaus, Economía, McGraw-Hill Interamericana de España, España, 2002.

Semarnap (2000), Guía forestal, Secretaría del Medio Ambiente, Recursos Naturales y Pesca, México.

Semerena, R. y F. Aroche, El Sector forestal mexicano: paradojas de la explotación de un recurso natural, Universidad Nacional Autónoma de México, México, 2000.

The World Bank, World Development Indicator, Development Data Center, EU, 2002.

The World Bank, "Five Years after Rio, Innovations in Environmental Policy", Environmentally Sustainable
Development Studied and Monographs, Serie núm. 19, EU, 1997.

Wallerstein, Immanuel, El moderno sistema mundial, Siglo XXI Editores, México, 1999 (9 ${ }^{a}$ ed. en español), vol. 1.

_ (1997), "El ascenso del este, o el sistema mundo en el vigésimo primer siglo, en: Iwaller@bingamton.edu.

White, A. y A. Martin, "¿De quiénes son los bosques del mundo? Tendencia forestal y bosques público en transición", en Forest Trends, Center for International Law, Washington, 2002.

WRM, "México: el comienzo de la invasión de plantaciones, dentro de la campaña plantaciones; plantaciones forestales impactos y luchas", 2001, en: http://www.wrm.org.uy/plantaciones/material/impactos3.html.

- (2000), "Costa Rica: los peligros de los monocultivos forestales", boletín núm. 39, en: http://www. wrm.org.uy/plantaciones/material/impactos3. html. 